\title{
Quinones as Dienophiles in the Diels-Alder Reaction; History and Applications in Total Synthesis
}

\author{
Christopher C. Nawrat and Christopher J. Moody*
}

In the canon of reactions available to the organic chemist engaged in total synthesis, the Diels-Alder reaction is among the most powerful and well understood. Its ability to generate rapidly molecular complexity through the simultaneous formation of two carbon-carbon bonds is almost unrivalled, and this is reflected in the great number of applications of it reported in the literature. Historically the use of quinones as dienophiles is highly significant being the very first example investigated by Diels and Alder. Herein we review the application of the Diels-Alder reaction of quinones in the total synthesis of natural products. The highlighted examples span some 60 years from the landmark syntheses of morphine and reserpine by Gates and Woodward respectively in 1952 and 1956, through to the present day examples such as the tetracyclines.

\section{History and importance of the Diels-Alder reaction}

Although the $[4+2]$-cycloaddition reaction now bears the names of Professor Otto Diels and his student Kurt Alder for their seminal publication in $1928,{ }^{[1]}$ history could easily have been otherwise. Indeed, in the two decades preceding their work, some of the greatest organic chemists of the day, including Thiele, Zincke ${ }^{[2]}$ and von Euler, ${ }^{[3]}$ had already unknowingly observed the reaction occurring. ${ }^{[4]}$ The reaction studied by Diels and Alder was that between cyclopentadiene and benzoquinone, which gave a mixture of mono- and di- adducts (1 and 2), and it was the successful identification of the products, the formation of which was inexplicable with the chemistry known at the time, that ensured them a place in history (Scheme 1).

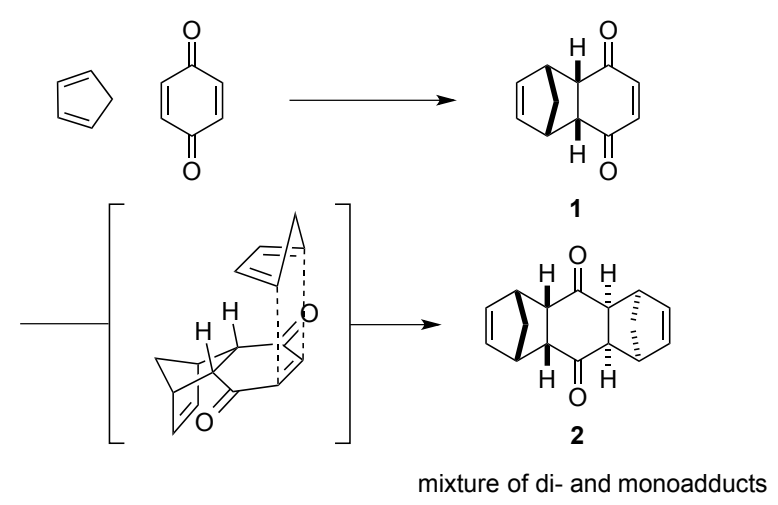

Scheme 1. The reaction observed by Albrecht and later by Diels and Alder.

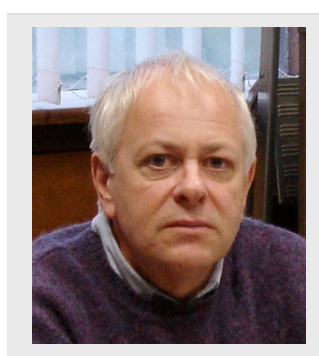

Chris Moody is the Sir Jesse Boot Professor in the

University of Nottingham. He graduated from King's College, London, before a PhD at Liverpool (C. $W$.

Rees) and postdoctoral work at ETH Zürich (A.

Eschenmoser). After a time in industry in 1979 he was appointed to a lecture-ship at 
In a remarkable feat of chemical prescience the pair were quick to recognize the potential applications of their reaction to the synthesis of natural products, and even speculated that it was used by Nature in the construction of terpenes. Famously, their seminal publication also contained an attempt to discourage other researchers from following up on their discovery: "We explicitly reserve for ourselves the application of the reaction developed by us to solving problems of this kind". A number of factors including greater interest in mechanistic aspects of the reaction than its applications, different motivation for carrying out total synthesis, which at the time was primarily a tool for structural determination, and the Second World War, meant that the synthetic chemistry community appeared to acquiesce to this demand until after Diels and Alder received their Nobel Prize in 1950. The following year, Stork and co-workers published a route to the natural product cantharidin. ${ }^{[5]}$ This was the first total synthesis to use the new reaction as a key step, although it should be noted that an unsuccessful Diels-Alder-based approach to the same target, culminating in the synthesis of desoxycantharidine, had been reported a decade earlier by a precocious 24 year old Robert Burns Woodward. ${ }^{[6]}$

Woodward had been fascinated by the Diels-Alder reaction since a young age, publishing a paper on its mechanism as sole author at the age of just $25 .{ }^{[7]}$ Indeed Woodward's interest in the Diels-Alder reaction went even further back, as wonderfully described in Lord Alexander Todd's perspicacious contribution to the Royal Society Biographical Memoir of RBW, co-authored with John Cornforth. ${ }^{[8]}$ Todd wrote "In a remarkable unpublished lecture delivered by him to the American Chemical Society in Chicago on 28 August 1973 on the occasion of his receiving (with Roald Hoffmann) the first Arthur Cope Award, Woodward stated that while still only eleven years of age he became aware through references in chemical textbooks which he read in the Boston Public Library that there existed journals which regularly published results of chemical research. He accordingly got in touch with the German ConsulGeneral in Boston, Baron von Tippelskirch and through him obtained specimen copies of the three main German periodicals Berichte der deutschen Chemische Gesellschaft, Journal für Praktische Chemie and Justus Liebig's Annalen der Chemie. The specimen of the last-named chanced to be the first issue of 1928 and contained the famous paper of Otto Diels and Kurt Alder announcing their discovery of the cycloaddition involving olefines and dienes known as the Diels-Alder reaction. The Diels-Alder paper fascinated Woodward who claimed that prior to reading the paper he had concluded that such a reaction must occur if one were to explain the separate existence - however transient - of the two Kekulé forms of benzene. However that may be, it is certain that his reading of that original paper in Annalen was the start of a lifelong interest, both practical and theoretical, in the Diels-Alder reaction, and so played an important role in the train of events leading finally to the development of the WoodwardHoffmann rules on orbital symmetry relations."

The early 1950s saw the publication of Gates' landmark synthesis of morphine ${ }^{[9]}$ and Woodward's steroid synthesis, ${ }^{[10]}$ and an explosion of new

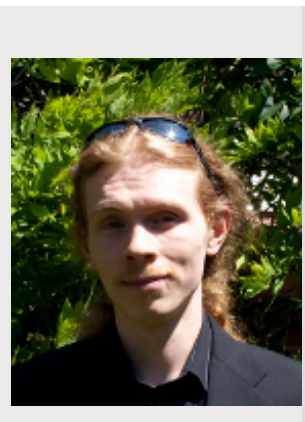
Chris Nawrat was born in Carshalton, England in 1986, and graduated from the University of Nottingham in 2008. He then joined the group of Chris Moody for his graduate studies on the total synthesis of naturally occurring quinones. He has recently moved to Princeton to undertake postdoctoral work with David MacMillan. applications for the reaction quickly followed as described in a number of excellent reviews. ${ }^{[1]}$ The floodgates had opened.

It is interesting to note the central role played by quinones in the Diels-Alder reaction throughout this early period. Not only did the first [4 +2$]$-cycloaddition identified by Diels and Alder employ a quinone dienophile, so did many of those previously observed but incorrectly explained. In fact, Albrecht (a student of Thiele) had performed the same reaction as that shown in Scheme 1 some two decades previously, but had misassigned the structures of the products and thus missed the significance of the chemistry he had performed. ${ }^{12]}$ Hans von Euler, who later won the Nobel Prize in Chemistry for his work on enzymes, had also witnessed the similar formation of a double adduct of isoprene with benzoquinone some years earlier but despite assigning the structure of this compound correctly, ${ }^{[3]}$ had been too busy with other projects to follow up on this remarkable result.

In fact, this trend in the use of quinones was maintained throughout the early decades following the seminal report by Diels and Alder. Although today such dienophiles are primarily used en route to 
quinonoid natural products, this was certainly not the case between the 1950s and 1980s when diverse targets spanning all the major classes of natural products were synthesised using the quinone Diels-Alder reaction. This is because, apart from their electron deficient nature, which makes them apt partners for electron rich or electron neutral dienes, quinones also contain useful chemical functionality that can form the basis for further transformations after the Diels-Alder reaction. This is important where - as is usually the case - the target molecule cannot be accessed directly by the use of a Diels-Alder reaction, and further synthetic operations are required to convert the cycloadduct into the final compound. Indeed, quinones themselves have been studied as chemical entities in their own right for over a hundred years, and have a rich and diverse chemistry that can be used to influence a synthetic route. The selection of examples that follow is not intended to be comprehensive - it is merely the authors' own perspective on an important part of the history of organic chemistry.

\section{Steroids}

Hundreds of different steroids are found throughout the animal and plant kingdoms. ${ }^{[13]}$ Their chemistry and biochemistry is among the best studied of any class of natural products, and their role in life as we know it, as hormones, drugs, and in cell membranes, is crucial. Their importance is underscored by the award of some five Nobel Prizes to seven chemists for work directly related to this family of compounds. As the Diels-Alder reaction is well suited to the preparation of substituted decalin systems, it is perhaps of little surprise that the reaction has been used extensively in the field of steroid synthesis. The quinone variant has also proved justifiably popular and has been employed by Woodward, ${ }^{[10]}$ Sarett, ${ }^{[14]}$ Dickinson, ${ }^{[15]}$ Wettstein, ${ }^{[16]}$ Walker, ${ }^{117]}$ and chemists from the Monsanto Chemical Company, ${ }^{[18]}$ among others. Although, as a consequence of the reaction's stereospecificity, the use of quinones as dienophiles will necessarily produce cis-decalins, the presence of the nearby carbonyl groups and the strong preference of such bicyclic systems to adopt a trans configuration facilitates epimerization to give the required ring-junction stereochemistry. Due to space limitations, only the syntheses of Sarett (1952), Woodward (1952), and Dickinson (1972) will be discussed here, as these developed the most new chemistry and conveniently exemplify three different orders of steroid ring construction; $\mathrm{BC} \rightarrow \mathrm{ABC} \rightarrow$ $\mathrm{ABCD}, \mathrm{CD} \rightarrow \mathrm{BCD} \rightarrow \mathrm{ABCD}$ and $\mathrm{AB} \rightarrow \mathrm{ABC} \rightarrow \mathrm{ABCD}$, respectively.

\subsection{3-Keto- $\Delta^{4,9(11), 16}$-etiocholatrienate (Woodward, 1951/52)}

Woodward was heavily involved in steroid chemistry during his early career, following his $\mathrm{PhD}$ studies on the use of the Diels-Alder reaction in 'a synthetic attack on the oestrone problem, 'i99]' He also famously collaborated with Konrad Bloch to unravel to the details of steroid biosynthesis, ${ }^{[20]}$ work for which the latter would be awarded the Nobel Prize in medicine in 1964, the year before Woodward received his in chemistry. In addition, Woodward also developed a groundbreaking route to racemic methyl 3-keto- $\Delta, 9(11), 16$-etiocholatrienate $\mathbf{8},{ }^{[10]}$ a flexible intermediate that retained sufficient functionality in rings $\mathrm{A}, \mathrm{C}$ and $\mathrm{D}$ to allow its conversion to a number of steroids, including cortisone and cholesterol, using known chemistry. Although quite lengthy and comparatively low yielding, this synthesis was among the first of a non-aromatic steroid and entailed the development of much new chemistry. Thus, the route began with the thermally promoted Diels-Alder reaction between 2-methoxy-5-methyl-1,4benzoquinone 3 and 1,3-butadiene in benzene that gave the expected cis-adduct $\mathbf{4}$ in excellent yield, even when carried out in batches of almost 300 grams (Scheme 2). Although it was the trans-decalin that was required as precursor to the steroid CD ring system, it had already been shown that cis-systems such as $\mathbf{4}$ could be easily epimerized to their thermodynamically more stable trans-diastereomers, and this was achieved by heating the initial Diels-Alder adduct with aqueous sodium hydroxide in dioxane followed by seeding the reaction mixture with the trans-isomer, which caused selective crystallization of the desired product. Next, both ketones were reduced using lithium aluminium hydride to give the unstable diol 5, which upon treatment with acid was converted into enone $\mathbf{6}$. The $\alpha$-acetoxy group was removed reductively with zinc in acetic anhydride and a hydroxymethylene group was introduced in its place to give 7. This enabled the use of a Robinson annulation for the introduction of the C-ring before it was removed under the basic reaction conditions. In order to obtain a satisfactory yield for this step, the reaction required extensive optimization and was run over 300 times. ${ }^{[21]}$ From here, introduction of the Aring and resizing of the D-ring were all that was needed to reach the target compound $\mathbf{8}$ whose conversion into a number of important steroids had already been demonstrated. Woodward also progressed this material towards cholesterol but stopped five steps short, relying on a formal synthesis via the combined work of Bruce, ${ }^{[22]}$ Birch, ${ }^{[23]}$ Ruzicka ${ }^{24]}$ and Butenandt. ${ }^{[25]}$ 
<smiles>COC1=CC(=O)C(OC)=CC1=O</smiles><smiles>COC1=CC(O)C2(C)CC=CCC2C1O</smiles>

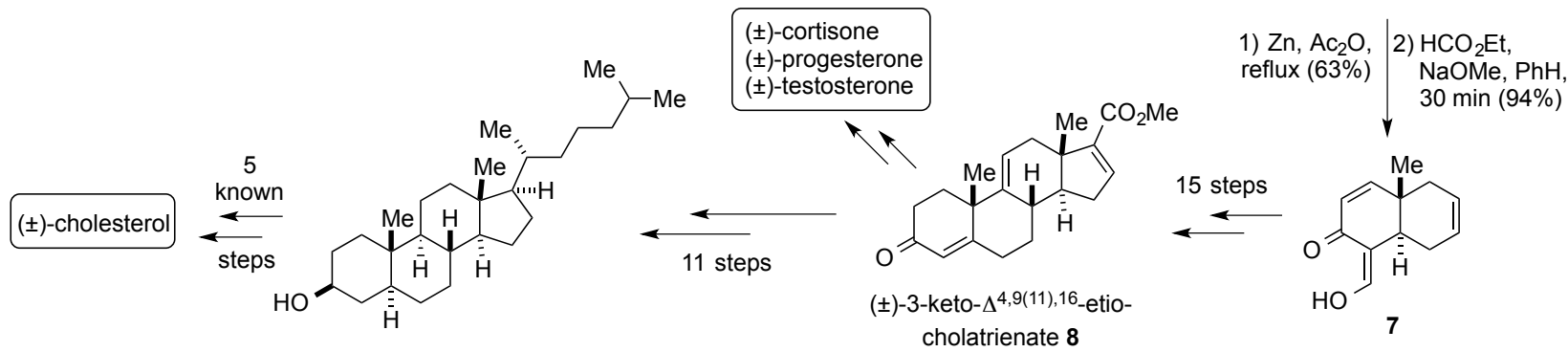

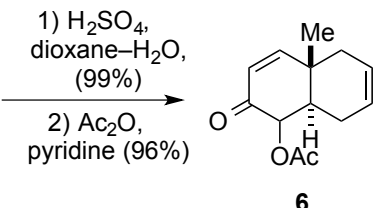

6

Scheme 2. Woodward's formal syntheses of racemic cortisone, progesterone, testosterone and cholesterol $(1951 / 52)$.

\subsection{Cortisone}

\subsubsection{Sarett (1952)}

Between 1952 and 1954 Lewis H. Sarett and co-workers at Merck published an impressive 13 part series of papers describing in detail their studies culminating in the total synthesis of cortisone, a highly sought after steroid particularly during the Second World War. ${ }^{[14,26]}$ Although their route was designed with only cortisone in mind, unlike Woodward's it used no relay compounds to replenish supplies of material in its advanced stages, and thus the target was completed without help from Nature. The quinone Diels-Alder reaction was again used early in the synthetic route to provide large quantities of a suitably functionalized decalin building block, but in this instance it was the BC ring system formed first. The two components in this reaction were the activated diene 9 and 1,4-benzoquinone itself, which were combined without solvent in one of the first examples of the use of an activated diene in a Diels-Alder reaction as part of a total synthesis (Scheme 3). The initial adduct obtained from this reaction was quite unstable to storage as well as being sensitive to both mildly acidic and basic conditions, and was therefore immediately reduced to more stable diketone $\mathbf{1 0}$ using Raney nickel and one equivalent of hydrogen gas. In order to attach the A-ring, both carbonyl groups in $\mathbf{1 0}$ were reduced using lithium aluminium hydride and the enol ether was then unmasked by treatment with acetic acid in water. Finally, Robinson annulation with methyl vinyl ketone (MVK) and Triton B gave tricyclic enone 11. From this point an additional 24 steps were then required to complete the racemic synthesis of the target, although the resolution of a number of intermediates was demonstrated, allowing for a potential preparation of either enantiomer of the natural product.<smiles>C=CC(=CC(C)=O)OCC</smiles>

9

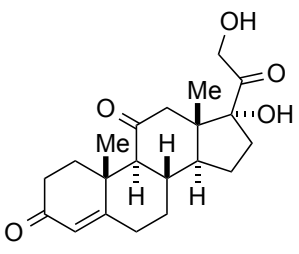

( \pm -cortisone

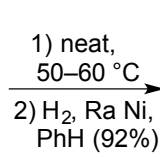

$\mathrm{PhH}(92 \%)$

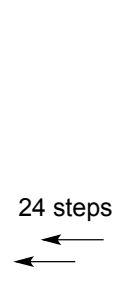<smiles>CCOC1=CC[C@H]2C(=O)CCC(=O)C2C1[N+](=O)[O-]</smiles>

10

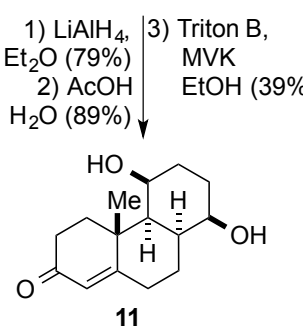

Scheme 3. Sarett's BC-first approach to the synthesis of racemic cortisone (1952). 
In 2004, E. J. Corey reported a new chiral cationic oxazaborolidinium catalyst for the Diels-Alder reaction that enabled him to carry out a formal synthesis of $(+)$-cortisone via Sarett's route. ${ }^{[27]}$ Originally, Sarett had relied on the late-stage resolution of the brucine salt of an advanced tricyclic intermediate to provide enantiomerically enriched material in low yield, with the inevitable loss of half the compound, making the efficient preparation of $(+)$-cortisone challenging. Corey employed a similar initial DielsAlder reaction to Sarett's, although the more readily accessible and robust diene $\mathbf{1 2}$ was used in place of enol ether 9 (Scheme 4). In the presence of $20 \mathrm{~mol} \%$ of reusuable catalyst $\mathbf{1 3}$, the reaction between diene 12 and 1,4-benzoquinone proceeded in 95\% yield and 90\% ee, with perfect regio- and diastereoselectivity. Diketone 14 was then converted into diol 15 using similar chemistry to that employed by Sarett, and could be recrystallized to $99 \%$ ee, thus achieving the formal total synthesis of (+)-cortisone.

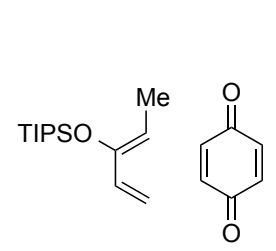

12

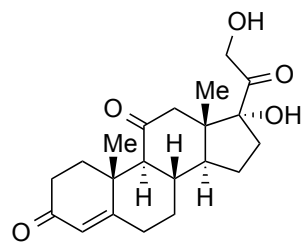

(+)-cortisone

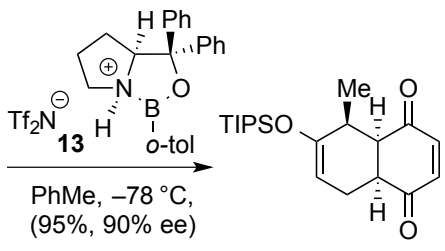

14

1) $\mathrm{H}_{2}, \mathrm{Ra} \mathrm{Ni}$, 3) $10 \%$ 2) $\mathrm{LiAlH}_{4}, \quad \mathrm{MeCN}$ THF $(82 \%) \downarrow \quad(92 \%)$
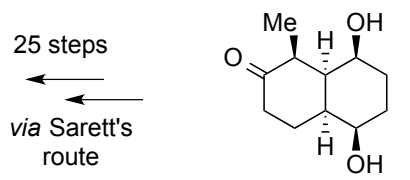

15

(recrystallized to $99 \%$ ee)

Scheme 4. Corey's enantioselective synthesis of Sarett's diol 15 (2004).

\subsection{Estrone Methyl Ether (Dickinson, 1972)}

In 1960, Eaton and Yates published the first report of the dramatic accelerating effect of aluminium trichloride on a number of Diels-Alder reactions, including several employing benzoquinone as a dienophile. ${ }^{[28]}$ One of the first published total syntheses to take advantage of this seminal report of Lewis acid catalysis (along with Kishi's 1972 synthesis of tetrodotoxin - see Section 3.4) was Dickinson's synthesis of estrone methyl ether in $1972 .{ }^{15]}$ Here, the Diels-Alder reaction between aryl diene 16 and benzoquinone 17 could be performed at room temperature in the presence of a slight excess of $\mathrm{BF}_{3} \cdot \mathrm{OEt}_{2}$ to give the Diels-Alder adduct 18 in good yield (Scheme 5). The regiochemical outcome of this reaction is interesting; when conducted in the presence of $\mathrm{BF}_{3} \cdot \mathrm{OEt}_{2}$, in addition to the major desired product 18 $(69 \%)$, a small amount of the regioisomeric Diels-Alder adduct was also obtained (14\%). However, in the absence of a Lewis acid, if the two components were simply heated in benzene, then the undesired regioisomer was the sole product. Although the ability of Lewis acids to alter the regiochemical outcome of cycloadditions is now a well understood phenomenon, this was the first report of such an additive being used to deliberately overturn the preferred course of a Diels-Alder reaction. Next, the endo-cisadduct 18 was converted into its corresponding trans-epimer 19 in quantitative yield by heating with sodium bicarbonate in methanol. Selective removal of one of the quinone carbonyl groups, followed by resizing of the D-ring then gave the target estrone methyl ether in 10 steps (Scheme 5). Although not the shortest synthesis of estrone at the time of publication, Dickinson's work was an important demonstration of the power of Lewis acids, and a harbinger of the many modern methods for asymmetric catalysis of the reaction. 


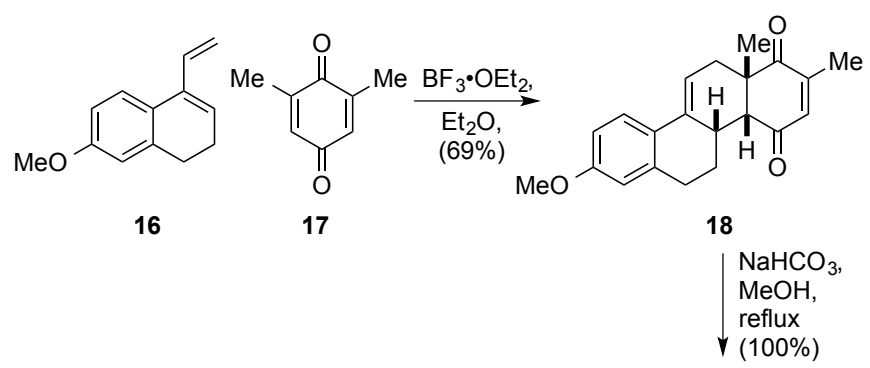

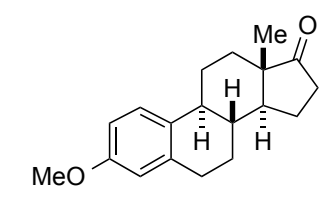

$( \pm)$-estrone methyl ether

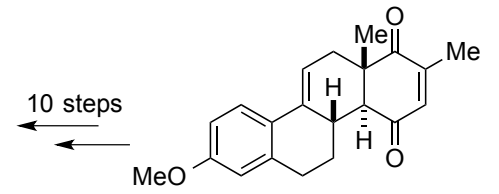

19

Scheme 5. Dickinson's total synthesis of racemic estrone methyl ether using a Lewis acid-catalyzed quinone Diels-Alder reaction (1972).

\section{Alkaloids}

\subsection{Morphine (Gates, 1952)}

Marshall Gates' 1952 synthesis of morphine, carried out at the University of Rochester, was historic for many reasons. It was the first total synthesis of an alkaloid that had been studied by chemists in one form or another for over 150 years, it vindicated the widely criticized structural assignment made by Robinson and Gulland in $1925,{ }^{[29]}$ and it showed that even Nature's most intricate molecules could succumb to a determined synthetic campaign. It was also one of the first total syntheses to feature the Diels-Alder reaction as a key step, employing an unusual ortho-quinone dienophile. ${ }^{[9,30]}$ The route began from 2,6-dihydroxynaphthalene 20, from which 12 steps were required to reach the ortho-quinone dienophile 21 (Scheme 6). Upon heating with 1,3-butadiene in dioxane in a sealed vessel quinone 21 underwent the expected Diels-Alder reaction, followed by tautomerization to give hydroxyenone $\mathbf{2 2}$ in reasonable yield. Cycloadduct 22 was heated with copper chromite in ethanol under a hydrogen atmosphere causing it to undergo an unusual reductive cyclization (which Gates had studied jointly with Woodward some years earlier $)^{[1]}$ to give lactam 23. The B-ring ketone was then removed under WolffKishner conditions in remarkably high yield and methylation of the amide, followed by reduction to the tertiary amine using lithium aluminium hydride, gave 24. From here a further 11 steps, including resolution with dibenzoyl $(+)$-tartaric acid, were required to complete the natural product. 


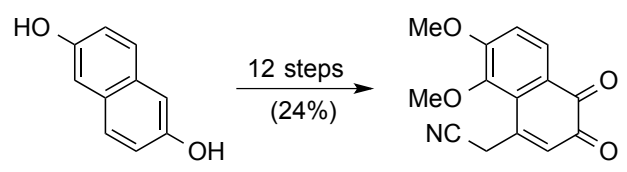

20

21

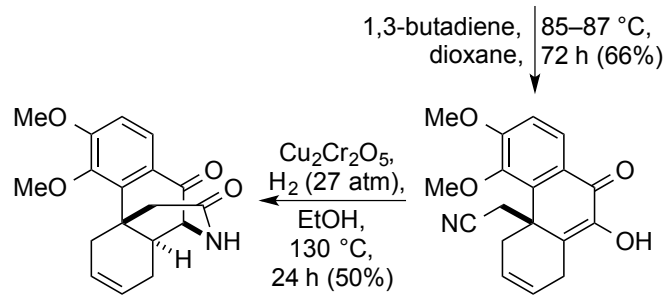

23

22

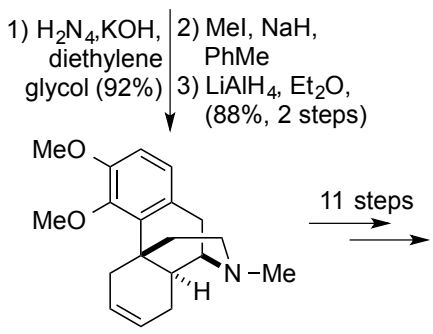

24

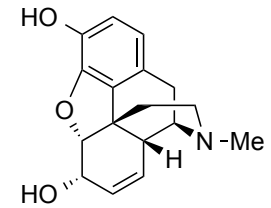

(-)-morphine

Scheme 6. Gates' landmark synthesis of morphine using an ortho-quinone dienophile (1952).

\subsection{Reserpine (Woodward, 1956)}

Reserpine is a classic target that in addition to its powerful sedative, antipyretic and antihypertensive properties, was made even more famous by Woodward's brilliant total synthesis, achieved just a year after its structural elucidation was reported. Since then, reserpine has become something of a benchmark for total synthesis, having been worked on by some of the greatest organic chemists of the past 50 years. The enduring popularity of this molecule, and indeed the wider family of yohimbine alkaloids (of which reserpine is perhaps the archetypal example), is evidenced by the report of one new total synthesis already this year, ${ }^{[32]}$ as well two new synthetic approaches published in 2012. ${ }^{[33]}$ Although Woodward's synthesis of this target, perhaps one of his finest, has been discussed in many compilations of classic syntheses, ${ }^{[34]}$ and in a review on approaches to reserpine, ${ }^{[35]}$ it would be impossible to omit it from a history of the quinone Diels-Alder reaction. Woodward's original route began with the Diels-Alder reaction between vinylacrylic acid 25 and 1,4-benzoquinone on a grand scale of $3.5 \mathrm{Kg}$ in some 5 gallons of boiling benzene (Scheme 7). ${ }^{[36]}$ Although the yield for this reaction was quite poor, due to the problem of irreversible aromatization of the initial adduct, it still produced over $2 \mathrm{Kg}$ of product each run, providing ample material for the rest of the investigation. The cyclohexene formed in the reaction would go on to become the reserpine E-ring, and this single step succeeded in setting three out of the five contiguous stereogenic centres required for this role, placing a carboxyl group in the correct location and providing "a double bond of good augury for the introduction of oxygen atoms" at the remaining two positions. Next it was necessary to find a way to differentiate between the two carbonyl groups, and the group discovered that when the sodium salt of the Diels-Alder adduct was treated with sodium borohydride in water, regioselective reduction occurred to give the hydroxyacid $\mathbf{2 6}$ (which did not spontaneously lactonize). Epoxidation of the most electron rich olefin, which unsurprisingly occurred from the convex face, was then carried out using perbenzoic acid and the transannular lactone was formed by treatment with acetic anhydride to give the caged compound 27. When this was subjected to Meerwein-PonndorfVerley reduction conditions, a remarkable sequence of reactions took place, including reduction of the ketone, transesterification to give the 5-membered lactone, epoxide opening by the allylic alcohol liberated and elimination of water. The resulting crude $\alpha, \beta$-unsaturated ester obtained was then treated with sodium methoxide to give conjugate addition product methyl ether $\mathbf{2 8}$ in a remarkably good yield considering what had been achieved. Treatment of this tetracycle with NBS in dilute sulfuric acid effected regio- and stereo-selective bromohydrin formation, with opening of the bromonium ion presumably directed by hydrogen bonding to the lactone. Oxidation of this intermediate with acidic chromium trioxide then gave an $\alpha$-bromoketone, which when treated with zinc in acetic acid underwent another impressive cascade comprising fragmentation of the bromoketone to give the enone and reduction of the lactone. Esterification with diazomethane and acetate protection of the free hydroxyl then yielded 
intermediate 29, which contained all five of the E-ring stereogenic centres set with essentially perfect control. Now that the rigid decalin system had performed its role in allowing the use of substrate control to introduce the required substituents with the correct stereochemistry the unwanted cyclohexenone ring could be removed. Thus, dihydroxylation with osmium tetroxide, followed by oxidative cleavage with loss of a carbon atom gave the acid, converted into the diester $\mathbf{3 0}$ by treatment with diazomethane. From here, only nine steps including a resolution were required to complete the natural product.

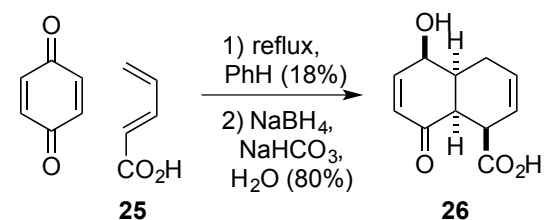

26

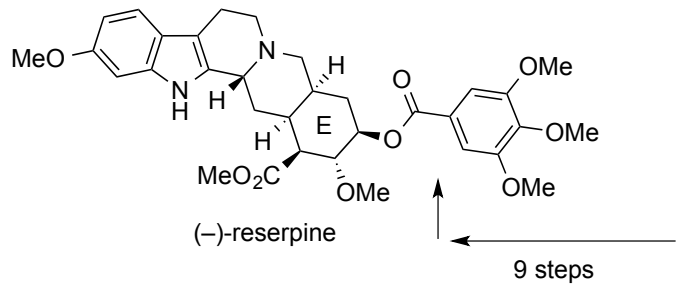

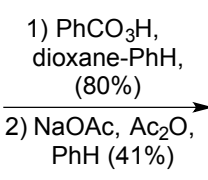
$\mathrm{PhH}(41 \%)$

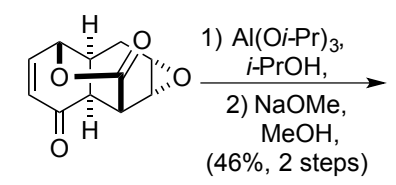

27

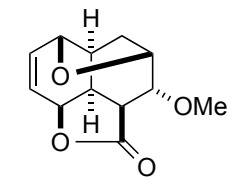

28

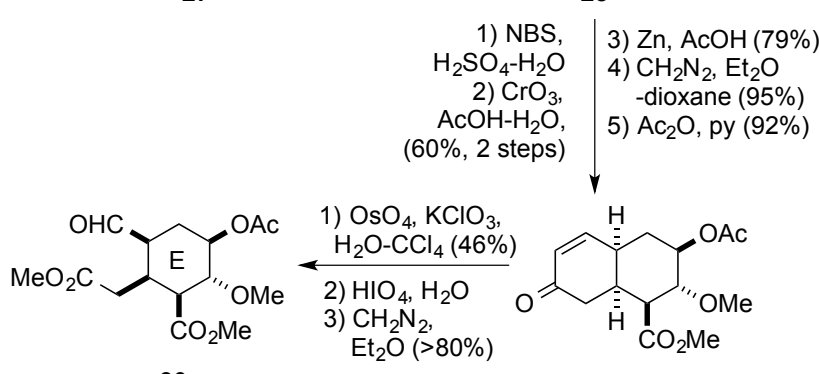

30

Scheme 7. Woodward's original route to reserpine (1956).

Later in the same year Woodward also published a brief one-page communication describing an even shorter route to tetracyclic ether 28. ${ }^{[37]}$ Using knowledge gained from the studies detailed above, it was possible to remove two steps from the previous sequence to prepare $\mathbf{2 8}$ in just four steps from 1,4benzoquinone (Scheme 8). The new route began with a slightly different Diels-Alder reaction between 1,4-benzoquinone and methyl vinylacrylate 31. This step, which was not extensively optimized, proceeded in much lower yield than the original Diels-Alder reaction, giving decalin $\mathbf{3 2}$ in just $8 \%$ yield. However, although in theory the same intermediate $\mathbf{3 2}$ could also be accessed by esterification of the Diels-Alder adduct obtained from the previous sequence (Scheme 7), this was attended by significant losses due to aromatization (under acidic conditions) or side reactions (with diazomethane). Reduction of both carbonyl groups under Meerwein-Ponndorf-Verley conditions also caused spontaneous lactonization (selectively forming the more stable 5-membered ring), and intramolecular bromoetherification of the remaining alcohol then gave tetracycle 33. Again, both reactions occurred from the convex face of the ring system with near-perfect stereocontrol. Displacement of the bromine atom in 33 by methoxide then occurred with retention of stereochemistry, presumably via E1cB loss of bromide followed by conjugate addition of methanol, to give $\mathbf{2 8}$.

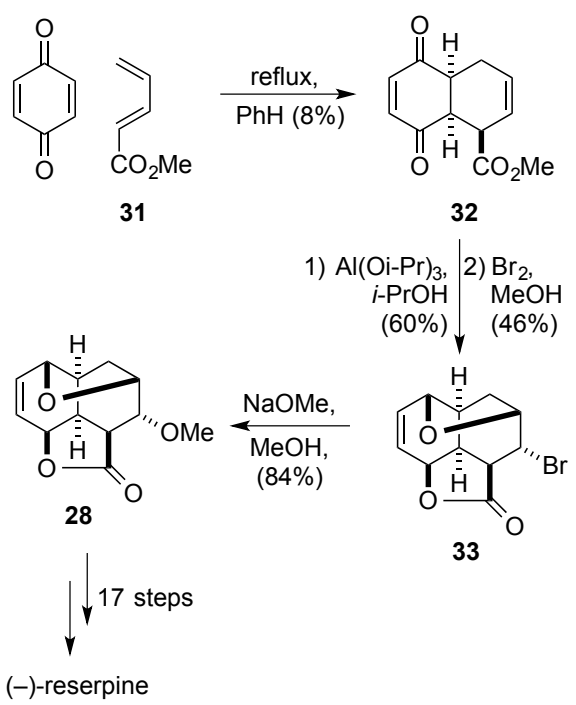

Scheme 8. Woodward's second generation route to lactone 28 (1956). 


\subsection{Ibogamine}

Ibogamine, along with ibogaine and catharanthine, belongs to a unique group of isoquinuclidinecontaining indole alkaloids that have been isolated from a number of plants including Tabernathe iboga and Catharanthus roseus and (also known as Vinca rosea). In addition to their own biological properties and unusual structures, the role of the Iboga alkaloid catharanthine in the biosynthesis of the potent anticancer compounds vincristine and vinblastine has made members of this family popular targets for total synthesis.

\subsubsection{Sallay (1968)}

In 1968 in another contribution from industry (Wyeth Laboratories), Stephen Sallay reported a short synthesis of racemic ibogamine based on a concise route to tricyclic azepanone 38; a key intermediate from which a number of Iboga alkaloids can be accessed by Fischer indole synthesis using different arylhydrazines (Scheme 9). ${ }^{38}$ Sallay's route to this key compound began with the Diels-Alder reaction between 1,3-hexadiene 34 and 1,4-benzoquinone, followed by removal of the remaining quinone double bond by reduction with zinc in acetic acid to give the diketone in good yield. Next, selective protection of the least hindered diketone carbonyl by dioxolane formation with ethylene glycol gave monoketal $\mathbf{3 5}$. The remaining ketone in $\mathbf{3 5}$ was converted into the oxime and heated with tosyl chloride in pyridine to effect a Beckmann rearrangement to give lactam 36 in excellent yield. From here, introduction of a tosyloxymethyl group and adjustment of protecting groups gave $\mathbf{3 7}$ in nine steps, from which the key tricyclic intermediate $\mathbf{3 8}$ was obtained by intramolecular alkylation upon heating in amyl alcohol.
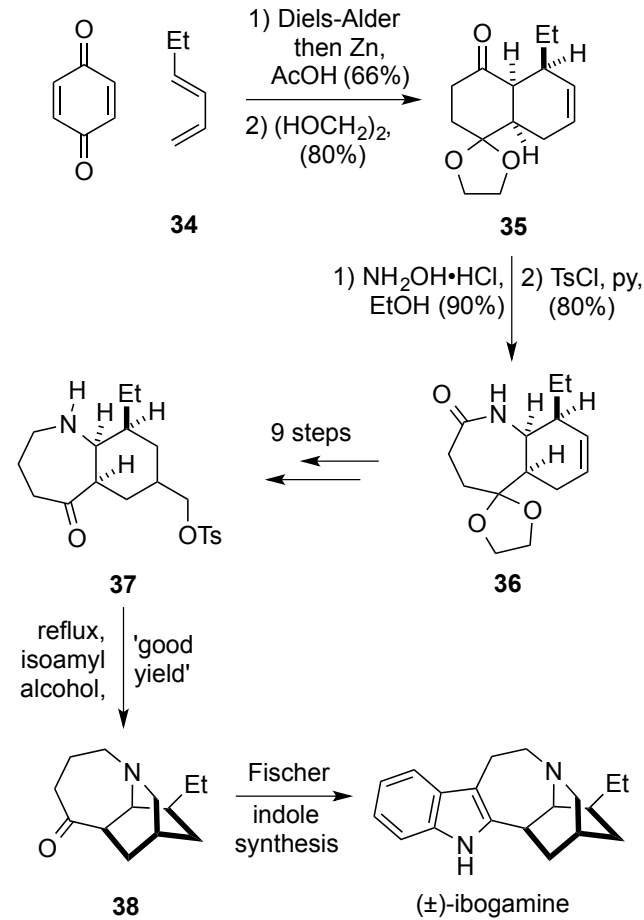

Scheme 9. Sallay's total synthesis of racemic ibogamine (1968).

\subsubsection{White (2000)}

More than 30 years after the publication of Sallay's route, James D. White at Oregon State reported a modified version of this synthesis, containing one of the first examples of a quinone Diels-Alder reaction successfully rendered enantioselective by asymmetric Lewis acid catalysis. ${ }^{[39]}$ In addition to this new methodology, he also employed a more highly functionalized diene than that used by Sallay, which enabled the synthesis of (-)-ibogamine in just 14 steps. Unexpectedly, the yield and ee obtained from the Diels-Alder reaction between 1,4-benzoquinone and diene 39 (Scheme 10), catalyzed by $30 \mathrm{~mol} \%$ of $(S)$ BINOL-TiCl 2 , were found to vary significantly dependent on the source of the catalyst, and only Mikami's procedure for its preparation gave consistently good results. ${ }^{[40]}$ The Diels-Alder adduct, which was immediately reduced to diol $\mathbf{4 0}$ to prevent oxidation in air, was then converted into the natural product in 12 steps via diketone 41, using chemistry patterned on Sallay’s approach. 

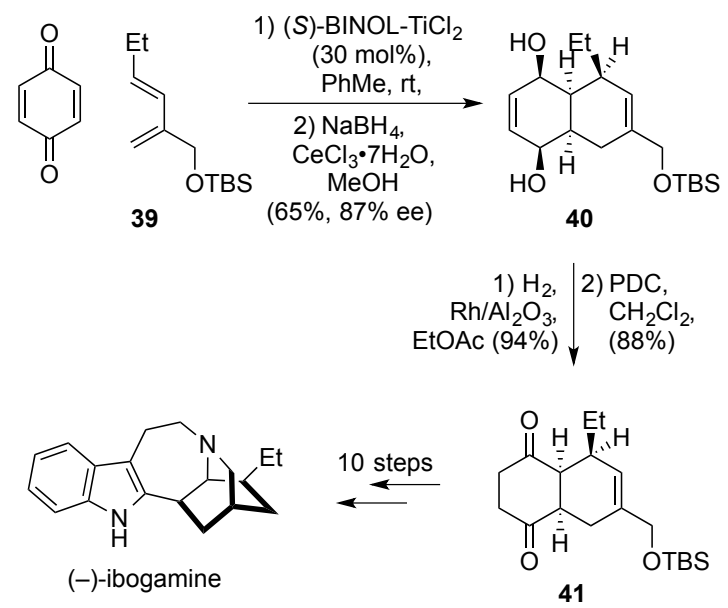

Scheme 10. White's asymmetric total synthesis of ibogamine (2000).

\subsection{Tetrodotoxin (Kishi, 1972)}

One of the first total syntheses to take advantage of the accelerating effect of Lewis acids upon the Diels-Alder reaction was Yoshito Kishi's classic 1972 synthesis of tetrodotoxin. ${ }^{[41]}$ This bold undertaking began with the Diels-Alder reaction between 1,3-butadiene and quinoneoxime 42, catalyzed by tin(IV) chloride, to give adduct $\mathbf{4 3}$ in excellent yield (Scheme 11). The oxime was then mesylated, and heating the activated species in water gave Beckmann rearrangement product acetamide 44. It is worth noting that although 44 is formally the Diels-Alder adduct of 1,3-butadiene with 2-acetamido-5-methyl-1,4benzoquinone, this reaction would in fact give the regioisomeric adduct, as cycloaddition occurs on the less electron rich double bond rather than the enamide. Thus Kishi's tactic of using the oxime as a latent acetamido- group therefore represents an ingenious solution to the problems created by the electron donating properties of amino-substituents. 

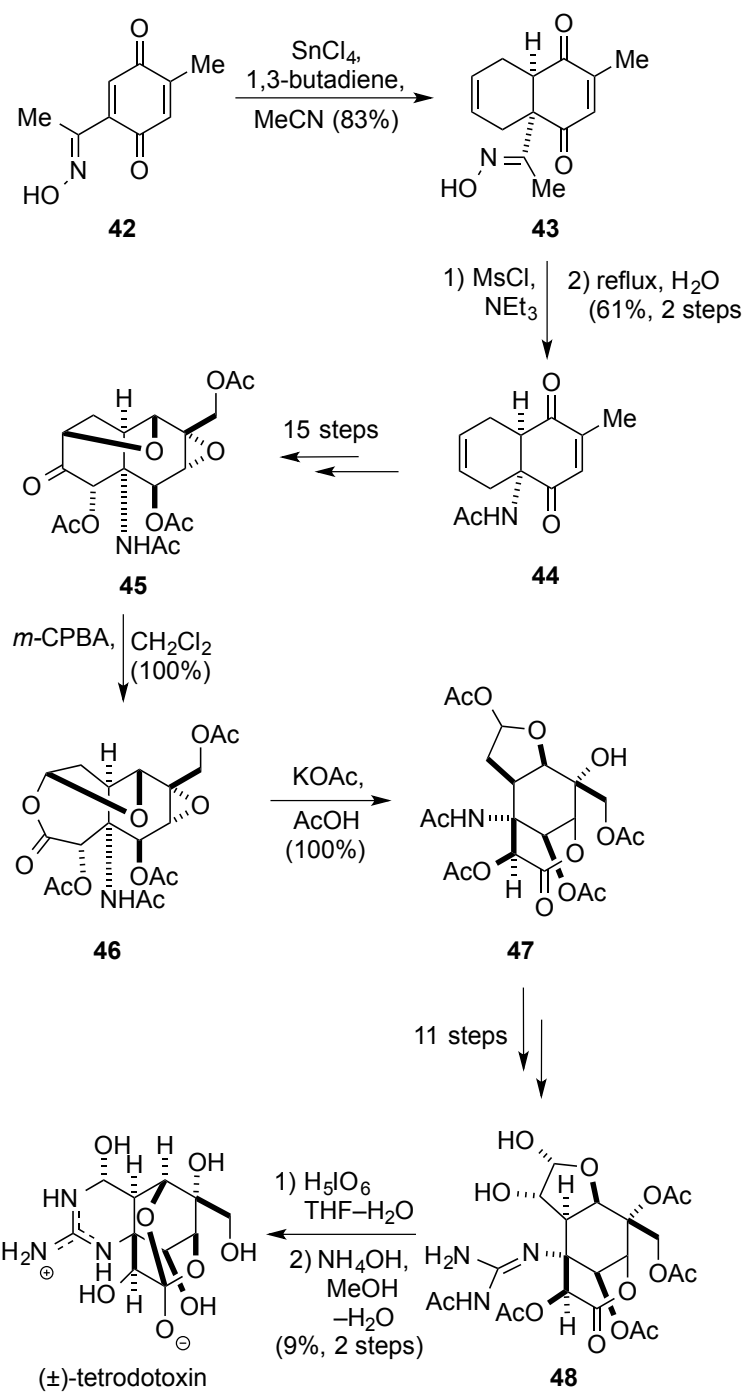

Scheme 11. Kishi's total synthesis of racemic tetrodotoxin (1972).

As in Woodward's reserpine synthesis, the rigid cis-decalin framework established by the Diels-Alder reaction was then used to guide the introduction of additional functionality under substrate control, leading to assembly of triacetate 45 in 15 steps. Having served its purpose of enabling stereoselective oxidation of the carbon skeleton, the decalone $\mathbf{4 5}$ was then subjected to Baeyer-Villiger oxidation and rearranged to give the tetracycle 46, which contained much of the core structure of the natural product. Adjustment of peripheral groups and introduction of the protected guanidine gave diol $\mathbf{4 8}$ that upon treatment with periodic acid underwent a second oxidative rearrangement. Final removal of all five acetyl protecting groups with ammonium hydroxide gave the natural product in a total sequence of 33 steps (Scheme 11).

\subsection{Dendrobine (Kende, 1974)}

In 1974 Andrew S. Kende and co-workers reported a concise total synthesis of racemic dendrobine using the quinone Diels-Alder reaction as a key step. ${ }^{[42]}$ Due to its antipyretic, hypotensive, and convulsant activity, as well as its compact and challenging structure, possessing seven contiguous stereocentres, this alkaloid has proven a popular target for synthetic chemists. In fact, Kende's approach remains among the shortest of the 12 total and formal syntheses of this molecule published so far, despite being only the third to appear in the literature. The route began with the Diels-Alder reaction between benzoquinone 49 and 1,3-butadiene, carried out in a sealed tube, to give, after methylation, adduct 50. Oxidative cleavage of the newly formed cyclohexene, followed by intramolecular condensation of the resulting dialdehyde gave enal 51. A double reductive amination with methylamine hydrochloride and sodium cyanoborohydride then formed tricyclic pyrrolidine $\mathbf{5 2}$ in modest yield. 1,2- 
Reduction of the enone with lithium aluminium hydride and treatment of the resulting allyl alcohol with acid led to formation of enone $\mathbf{5 3}$ that was converted into dendrobine in 5 steps (Scheme 12).

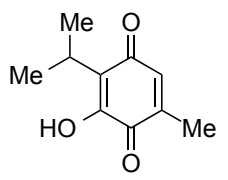

49

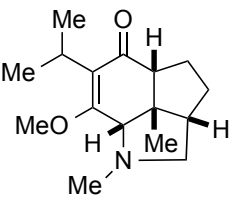

52

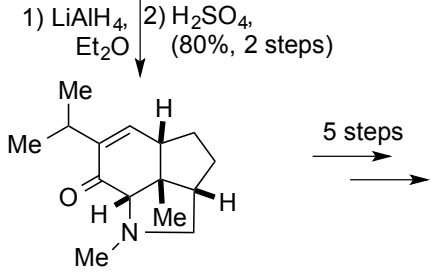

53

$(100 \%)$
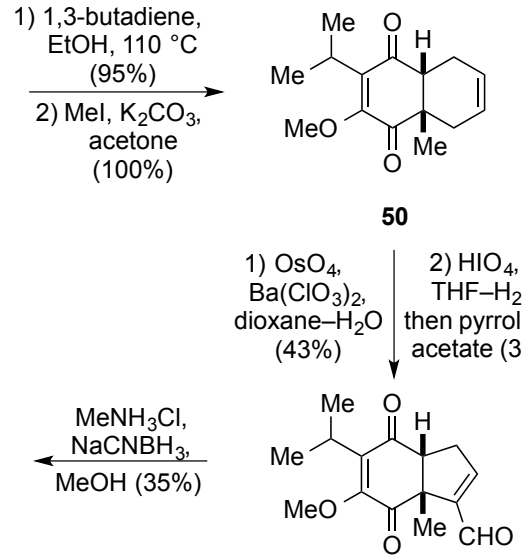

51

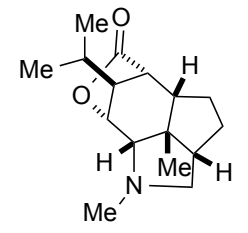

$( \pm)$-dendrobine

Scheme 12. Kende's total synthesis of racemic dendrobine (1974).

In 2004, Corey used a chiral cationic oxazaborolidinium catalyst to synthesize (-)-50 in $99 \%$ yield with $99 \%$ ee, thus achieving the formal total synthesis of $(-)$-dendrobine via Kende's route. ${ }^{[27]}$ This is particularly noteworthy as it was the first report of the asymmetric catalysis of a Diels-Alder reaction of butadiene itself in a natural product synthesis.

\section{Terpenoids}

\subsection{Gibberellic acid (Corey, 1978)}

In 1978 Corey and his Harvard co-workers achieved the first total synthesis of the important plant hormone gibberellic acid, winning a race between some 25 research groups that had collectively already produced over 150 papers. ${ }^{[4]}$ This pentacyclic diterpene, produced endogenously to control development and promote growth of cells, is obtained commercially from the pathogenic fungus Gibberella fujikuroi, and is one of a large number of gibberellins, all with potent effects on plant development. ${ }^{[45]}$ The route began with the Diels-Alder reaction of trans-2,4-pentadien-ol 54 with benzoquinone 55 that gave, after heating in benzene for 30 hours, a single product 56 in excellent yield (Scheme 13). The regioselectivity observed is presumably due to deactivation of the 4-carbonyl in the dienophile 55, which can be regarded as a vinylogous ester. Next, the group had planned to use the sequence developed in Woodward's synthesis of the steroids (viz. Scheme $2, \mathbf{4} \rightarrow \mathbf{6}$ ) to allow differentiation between the two carbonyl groups in 56, but as this was unsuccessful an alternative approach was developed. Thus, the primary alcohol was protected with a THP group, the more reactive ketone was reduced with sodium borohydride and the resulting alcohol was protected using the newly developed MOM protecting group to give vinylogous ester 57. 1,2-Reduction of the vinylogous ester, followed by treatment of the resulting allyl alcohol with mesyl chloride and elimination led to transposed enone $\mathbf{5 8}$ in good yield. Careful hydrogenation of $\mathbf{5 8}$ using a rhodium-on-carbon catalyst and one equivalent of hydrogen was then used to reduce only the enone double bond. Treatment of the resulting ketone with lithium in ammonia caused debenzylation and reduction of the carbonyl to give a diol, oxidation of which gave unstable keto-aldehyde $\mathbf{5 9}$ that was converted in nine steps into diene $\mathbf{6 0}$. When a solution of 60 and propylene oxide was heated to $160{ }^{\circ} \mathrm{C}$, an intramolecular endo Diels-Alder reaction occurred, forming the fourth ring of the natural product in moderate yield. Elimination of chloride, followed by alkylation with lithium isopropylcyclohexylamide 
and iodomethane in the presence of HMPA, gave lactone $\mathbf{6 1}$ that was converted into gibberellic acid in 12 additional steps.
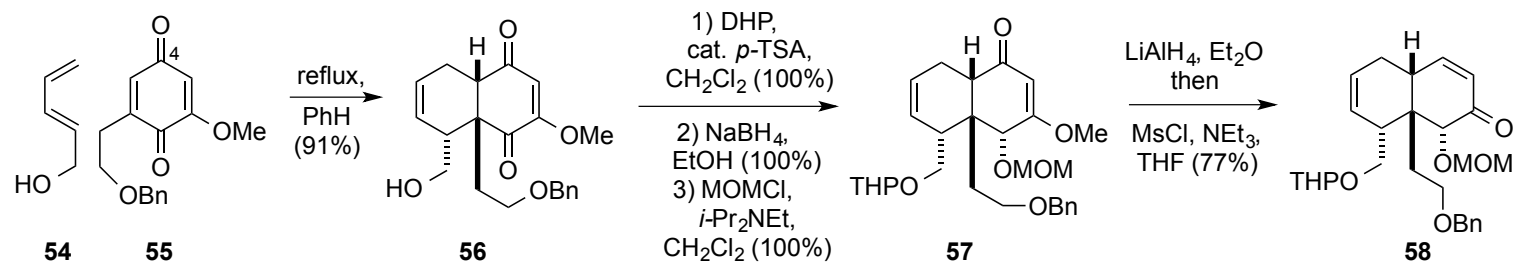

$\mathrm{CH}_{2} \mathrm{Cl}_{2}(100 \%)$

57

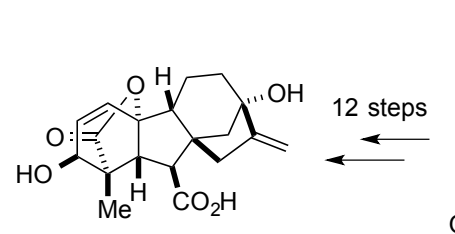

( \pm )-gibberellic acid

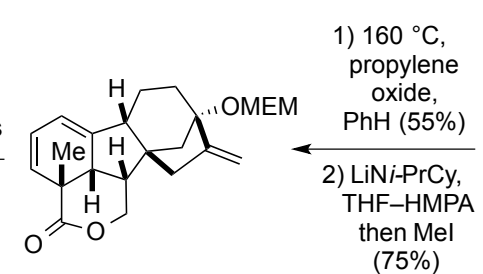

61

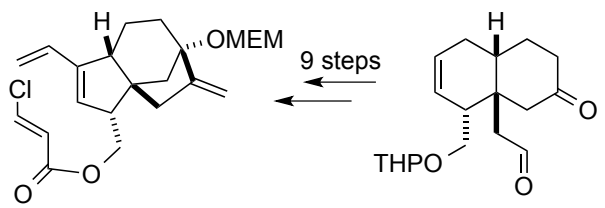

60

59

Scheme 13. Corey's synthesis of racemic gibberellic acid (1978).

\subsection{Hirsutene (Mehta, 1981)}

The linear triquinane hirsutene has proved an immensely popular target with more than a dozen different synthetic approaches described in the most recent review. ${ }^{[46]}$ A remarkable formal total synthesis of this natural product, ${ }^{[4]}$ which was also adapted to access the other linear triquinane natural products capnellene and coriolin, ${ }^{[48]}$ was developed by Goverdhan Mehta and co-workers at Hyderabad using nothing but heat and light for the first three steps. The route began with the known Diels-Alder reaction between 2,5-dimethyl-1,4-benzoquinone 62 and cyclopentadiene (Scheme 14). The endo-adduct 63 obtained was then exposed to UV light effecting an intramolecular [2 + 2]-photocycloaddition to give caged diketone 64 in excellent yield. This was then converted by flash vacuum pyrolysis (FVP) into a separable mixture of three linear triquinanes in quantitative yield. After sufficient quantities of bis(enone) $\mathbf{6 5}$ were obtained (by thermal equilibration of the mixture and separation of the desired compound), nine steps were required to complete the natural product.

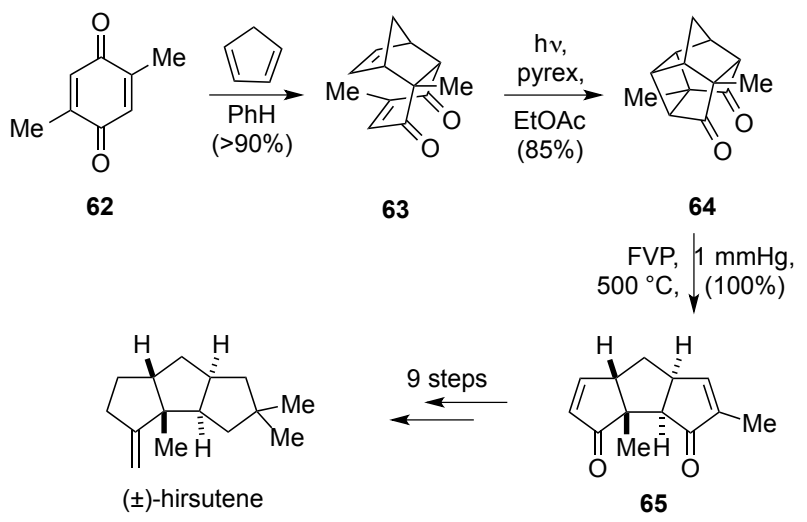

Scheme 14. Mehta's formal synthesis of hirsutene (1981).

\subsection{Myrocin (Danishefsky, 1994)}

In 1994 Samuel J. Danishefsky and co-workers at Yale reported an interesting total synthesis of the pentacyclic pimarane myrocin $C,{ }^{[49]}$ a natural product shown to have antitumour and broad spectrum antibiotic activity. They hypothesized that the compound might undergo bisalkylation in vivo via the generation of an active electrophilic species by cleavage of the hemiacetal and opening of the cyclopropane ring, and the group planned to investigate the mechanistic aspects of this sequence through the synthesis of analogues. The route began with a Diels-Alder reaction between diene 66, the product of a Birch reduction of TBS-protected ortho-cresol, and 1,4-benzoquinone that proceeded in excellent yield 
at room temperature to give adduct 67 (Scheme 15). An unusual Rubottom-type oxidation of the silyl enol ether 67 occurred upon treatment of this compound with DMDO, in which the TBS group was not lost but migrated to the newly installed oxygen, presumably in response to steric crowding around the adjacent methyl group. Reduction of both quinone carbonyls under Luche conditions gave hemiacetal 68, which conveniently allowed differentiation of the enediol hydroxyl groups. Acetylation of the free allylic alcohol, followed by TBS deprotection gave vicinal diol 69. Treatment with sodium periodate, followed by reduction and protection of the resulting aldehyde then gave tricyclic lactone $\mathbf{7 0}$ in excellent yield. Although this compound contained three of the five rings found in the natural product, introduction of the final cyclopropane and cyclohexene rings proved challenging and another 21 steps were required to reach the target.<smiles>CCCCOC1=C(C)CCC=C1</smiles>

66

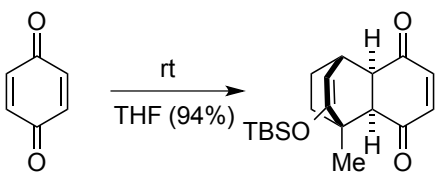

67

1) $\mathrm{DMDO}$, 2) $\mathrm{NaBH}_{4}$

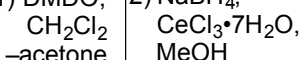
(62\%, 2 steps)

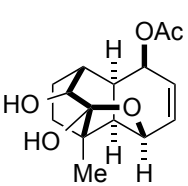

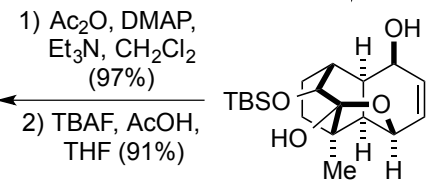

68

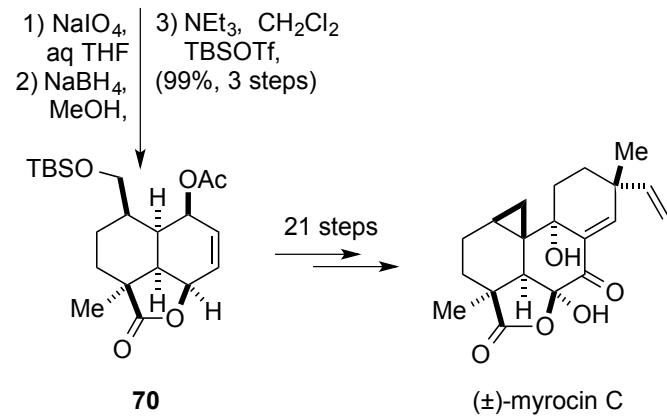

Scheme 15. Danishefsky's total synthesis of racemic myrocin C (1994).

\subsection{Colombiasin A and elisapterosin B}

Amongst all the organisms from which marine natural products have been isolated, the gorgonian soft corals have proven to be one of the richest sources of molecules with interesting structures and biological activites. Within this family, Pseudopterogorgia elisabethae has provided chemists and biologists with a range of diterpenes that have demonstrated anti-inflamatory, antituberculosis, ${ }^{[50]}$ analgesic, cytotoxic, ${ }^{[51]}$ antibacterial, and antimalarial properties. ${ }^{[52]}$ In the past decade, three families of compounds in particular have drawn the attention of the synthetic chemistry community due to their intricate cage-like structures, powerful biological activities and the intriguing possibility of biosynthetic relationships between their members: the colombiasins, ${ }^{[50]}$ elisapterosins ${ }^{[5069}$ and elisabethins (Figure 1). ${ }^{[51]}$ 

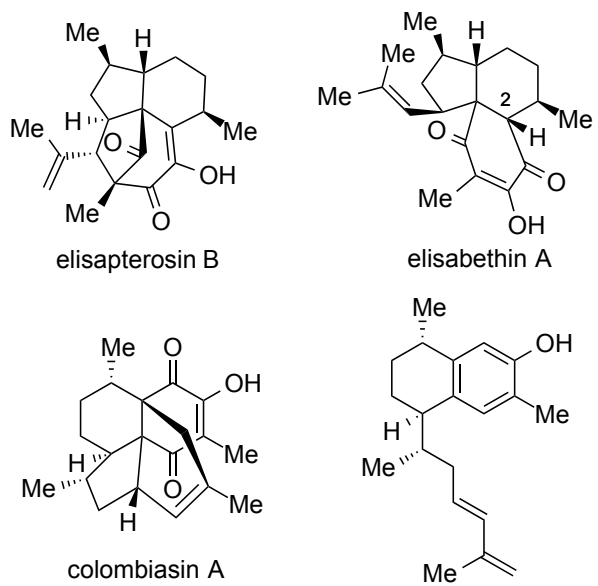

7-hydroxyerogorgiaene

(a serrulatane-type diterpene)

Figure 1. Representative natural products from $P$. elisabethae: elisapterosin $\mathrm{B}$, colombiasin $\mathrm{A}$ and their putative biosynthetic precursors elisabethin A and 7-hydroxyerogorgiaene.

As is the case for many natural products, the first group to publish a synthesis of one of these compounds was that of $\mathrm{K}_{55]} \mathrm{C}$. Nicolaou of the Scripps Institute in 2001, and since then Rychnovsky, Jacobsen, ${ }^{[5]}$ Harrowven, ${ }^{[55]}$ Rawal, ${ }^{[56]}$ and Davies ${ }^{[57]}$ have all reported syntheses of members of these closely related families. Perhaps unsurprisingly, given the polycyclic cyclohexene-1,4-dione core common to these compounds, all routes so far have employed at least one quinone Diels-Alder reaction. Although the following discussion is necessarily centred on the strategy surrounding the use of these reactions, broader coverage of synthetic efforts in this area have been included in other reviews. ${ }^{[58}$

\subsubsection{Nicolaou (2001)}

Nicolaou achieved the first total synthesis of colombiasin A in 2001, ${ }^{[59]}$ employing two different quinone Diels-Alder reactions as key bond forming steps. The first was that of simple diene $\mathbf{7 1}$ with methoxybenzoquinone 72, which was performed by simply stirring the two components together in ethanol (Scheme 16). The unstable initial adduct was then protected by methylation with iodomethane and potassium carbonate and the enol ether was hydrolyzed with TFA in dichloromethane to give tetralone 73. The diene-containing side chain required for the second, intramolecular, Diels-Alder reaction was introduced over a 10 step sequence and all that was required before the key intramolecular Diels-Alder reaction could be attempted was unmasking of the quinone; however, all attempts at oxidative demethylation of $\mathbf{7 4}$ failed. Fortunately, when the diene was protected as the corresponding sulfolene, oxidative demethylation could be carried out under Rapoport's conditions with silver(II) oxide and nitric acid to give quinone $75 .^{[60]}$ When 75 was heated to $180^{\circ} \mathrm{C}$ in toluene in a sealed tube, the diene was unmasked by cheleotropic extrusion of sulfur dioxide and underwent a second cycloaddition reaction with the nearby quinone to give tetracycle 76. Finally, removal of the extraneous hydroxyl group by Barton-McCombie deoxygenation gave colombiasin A. 


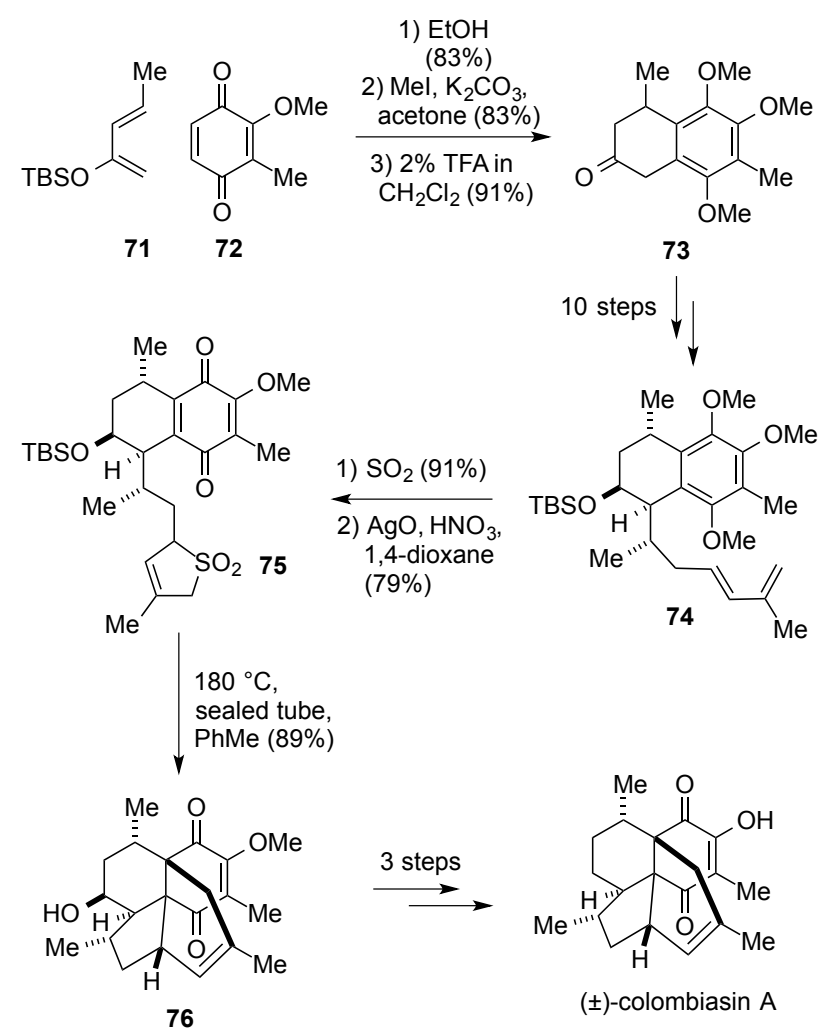

Scheme 16. Nicolaou's synthesis of ( \pm )-colombiasin A (2001).

Later in the year a second publication by the Scripps based group reported the determination of the absolute configuration of the natural product through the use of the Mikami catalyst (prepared from $(S)$ BINOL and $\left.\left[(i-\mathrm{PrO})_{2} \mathrm{TiCl}_{2}\right]\right)^{[40]}$ to render the initial Diels-Alder reaction enantioselective. ${ }^{[61]}$ Although the yield in this step was somewhat diminished by the imperfect regioselectivity $(85: 15$ in favour of the desired product) obtained when the catalyst was used, the key building block 73 was obtained with $94 \%$ ee after methylation and hydrolysis. The enantio-enriched material $\mathbf{7 3}$ was carried through the previously reported sequence (Scheme 16) to give (-)-colombiasin, whose data matched that of the natural material, establishing for the first time its absolute stereochemistry.

\subsubsection{Rychnovsky (2003)}

The second total synthesis of (-)-colombiasin A came from Scott Rychnovsky's group at UC Irvine in $2003,{ }^{[53]}$ who again relied on two separate quinone Diels-Alder reactions at either end of the synthesis to construct the target. Interestingly, rather than use an asymmetric catalyst in the first as Nicolaou had, the group instead employed an enantioenriched diene and relied on substrate control to direct the outcome - a highly unusual tactic in the quinone Diels-Alder reaction. Diene 77 was prepared in just three steps, using a Myers alkylation and a Kowalski homologation as the key transformations. Reaction of the diene 77 with quinone 72 was carried out under Dailey's conditions $\left(5 \mathrm{M} \mathrm{LiClO}_{4}\right.$ in $\left.\mathrm{Et}_{2} \mathrm{O}\right)$ at room temperature, ${ }^{[62]}$ and the desired adduct 78 was obtained in a moderate $47 \%$ yield, although unfortunately this product was contaminated with $27 \%$ of an inseparable diastereomer that had to be carried through the remainder of the synthesis. The cycloadduct $\mathbf{7 8}$ was converted in seven steps into aldehyde 79, which was then subjected to Wittig reaction to form the diene side chain and deprotection, followed by aerial oxidation, to unveil the quinone dienophile 80. Heating this compound to $180{ }^{\circ} \mathrm{C}$ in toluene in a sealed tube successfully promoted the required intramolecular quinone Diels-Alder reaction, forming tetracycle $\mathbf{8 1}$ in good yield. Finally, demethylation with aluminium trichloride buffered with dimethylaniline gave colombiasin A, albeit as a 1.7:1 mixture of diastereomers as a result of the poor selectivity in the initial intermolecular Diels-Alder reaction. Fortunately, at this stage separation by flash column chromatography was finally possible, and a sample of the pure natural product could be obtained (Scheme 17). 

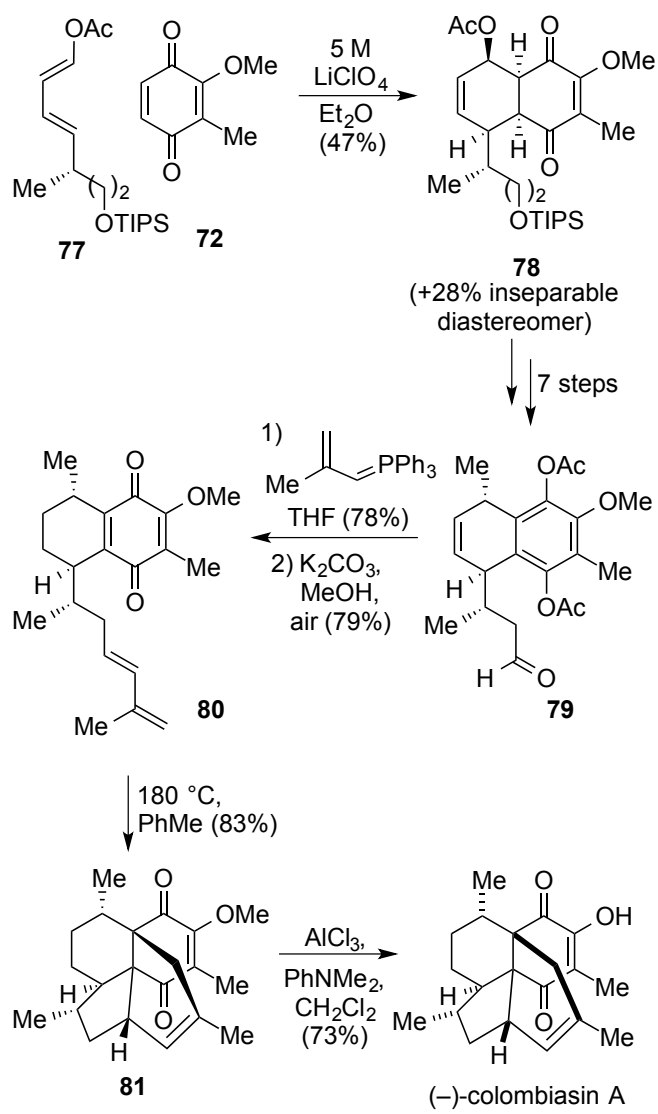

Scheme 17. Rychnovsky's substrate-controlled Diels-Alder approach to (-)-colombiasin A (2003).

Rychnovsky had deliberately designed his synthetic route to colombiasin A to proceed via diene $\mathbf{8 0}$ because of its similarity to the serrulatane family of diterpenes, the putative biosynthetic precursors to elisabethin $\mathrm{A},{ }^{[51]}$ from which colombiasin $\mathrm{A}$ and elisapterosin $\mathrm{B}$ are believed to be derived. Whereas colombiasin $\mathrm{A}$ is apparently the result of a [4 +2]-cycloaddition between the diene side chain and the nearby quinone, elisapterosin $\mathrm{B}$ appears to be the result of a much less common [5 + 2]-cycloaddition with the same moiety. After some optimization, it was found that treatment of $\mathbf{8 0}$ with a large excess of boron trifluoride at low temperature led to formation of a mixture of the [4 +2]-cycloadduct $(-)-O$-methyl colombiasin A (in 22\% yield) along with (-)-elisapterosin B (41\% yield), thus completing the first synthesis of this natural product.

\subsubsection{Rawal (2003)}

Based on a biosynthetic proposal suggested by Rodriguez, ${ }^{[51]}$ Viresh Rawal and his co-workers at the University of Chicago set out to prepare elisabethin A, then attempt its biomimetic conversion into the closely related diterpene elisapterosin B via an oxidative cyclization. ${ }^{[56]}$ The key step in the synthesis was an intramolecular quinone Diels-Alder reaction that simultaneously formed two of the three remaining rings (Scheme 18). The precursor to this step, dienyl quinone 82, was prepared efficiently in 15 steps from inexpensive L-glutamic acid. The expected Diels-Alder reaction of $\mathbf{8 2}$ occurred in good yield and selective hydrogenation of the disubstituted olefin $\mathbf{8 3}$ with Wilkinson's catalyst proceeded in quantitative yield. Only $O$-demethylation and C-2 epimerization were required to complete the first total synthesis of elisabethin A (albeit as the unnatural enantiomer). However, although $O$-demethylation could be carried out easily by heating with lithium iodide, epimerization of the C-2 centre could not be performed either before or after removal of the methyl group, even under forcing conditions. As elisabethin A itself could not be synthesized, the available 2-epi-compound $\mathbf{8 4}$ was instead used to investigate the conversion of this family of compounds into the elisapterosins; as the stereocentre at C-2 would be destroyed in this step, its configuration was of no consequence as long as the reaction still occurred. Fortunately, demethylation of ent-2-epi-elisabethin A $\mathbf{8 4}$ with lithium iodide followed by oxidation with CAN in acetonitrile and base-assisted enolization did cause conversion to ent-elisapterosin B in excellent yield. 

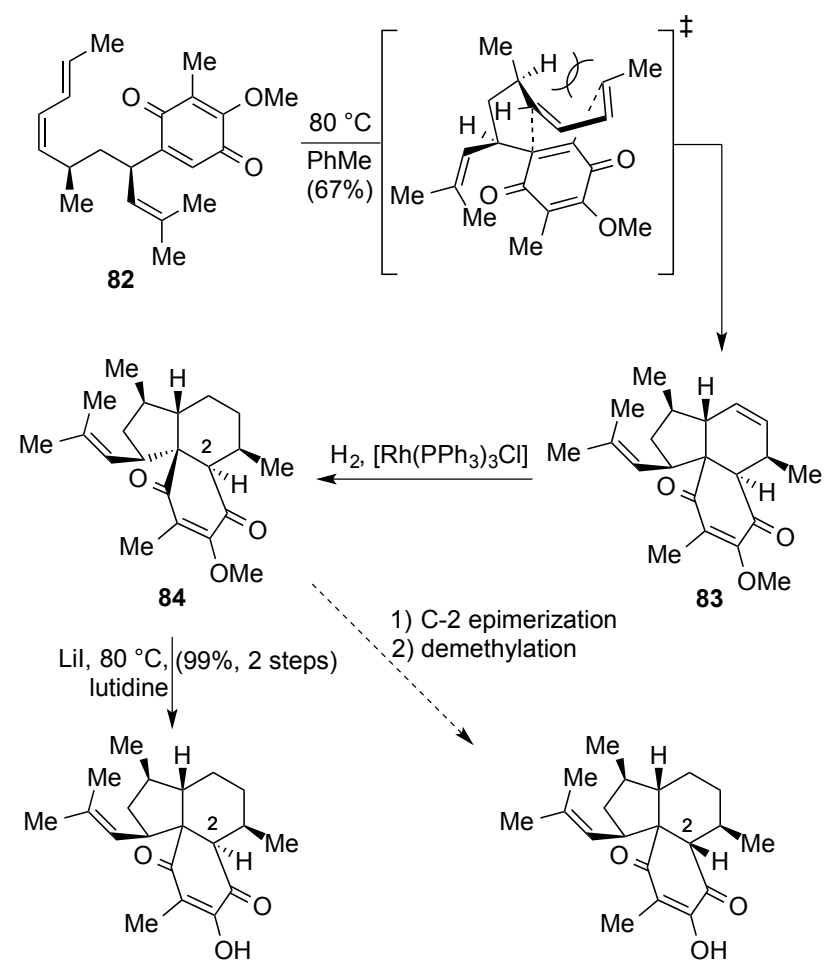

2) demethylation
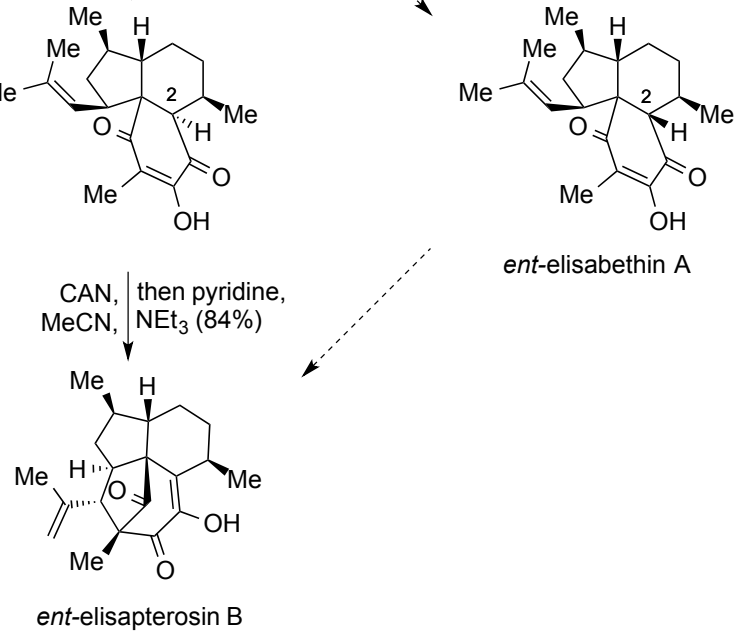

ent-elisabethin A

ent-elisapterosin $\mathrm{B}$

Scheme 18. Rawal's biomimetic synthesis of ent-elisapterosin B via ent-2-epi-elisabethin A (2003).

\subsubsection{Elisabethin A (Mulzer, 2003)}

Shortly before Rawal's synthesis of ent-2-epi-elisabethin A appeared in the literature, Johann Mulzer reported the first total synthesis of the elusive elisabethin A via a similar intramolecular Diels-Alder strategy, although working in the opposite (natural) enantiomeric series. ${ }^{[63]}$ Diene 85 was prepared in 14 steps with one stereocentre derived from the Roche ester, and the other set by Evans' asymmetric alkylation (Scheme 19). The latent quinone in $\mathbf{8 5}$ was unmasked by TBAF-mediated removal of the TBS protecting groups, followed by treatment of the hydroquinone with aqueous iron(III) chloride. Surprisingly, in contrast to the high temperatures employed by Rawal on the similar system 82, the desired intramolecular Diels-Alder reaction occurred spontaneously at room temperature under these almost biomimetic conditions to give tricyclic intermediate 86. The reaction was highly stereoselective with no other isomers observed in the proton NMR, and this outcome was originally suggested to arise via an endo transition state akin to that proposed by Rawal above (Scheme 18), but this was later corrected to the exo transition state shown in Scheme 19. ${ }^{[64]}$ The use of a diene containing a terminal $(Z)$ olefin is significant; this is one of the first reported examples of a successful intramolecular Diels-Alder reaction on a substrate of this type, as isomerization and slow reaction times frequently hamper their use. The relative stereochemistry of the Diels-Alder product $\mathbf{8 6}$ was confirmed by NOESY experiments, and it was duly subjected to hydrogenation, epimerization and deprotection to give what was presumed to be elizabethin A. However, since the publication of this synthesis a paper by Zanoni and co-workers has called into doubt the completion of the target. ${ }^{[65]}$ Based on an analysis of the literature precedent for similar Diels-Alder reactions it has been suggested that the proposed exo transition state is unlikely, and that either an endo transition state or isomerization of the diene under the reaction conditions might have led to the formation of a different diastereomer of $\mathbf{8 6}$ to that reported and hence a stereoisomer of the natural product. Furthermore, Zanoni points out the ease with which epimerization of $\mathbf{8 7}$ could be carried out by Mulzer, when Rawal was unable to epimerize its enantiomer 84 (Scheme 18), and when models 
suggest that this molecule exists in a conformation in which the $\mathrm{C}-2-\mathrm{H}$ bond is almost co-planar to the carbonyl $\mathrm{C}=\mathrm{O}$ bond. Based on these inconsistencies, and the non-superimposability of Mulzer's NMR spectroscopic data with that of the natural product, Zanoni concludes that "further work is required before elisabethin A can be placed in the basket of natural products whose synthesis has been completed".
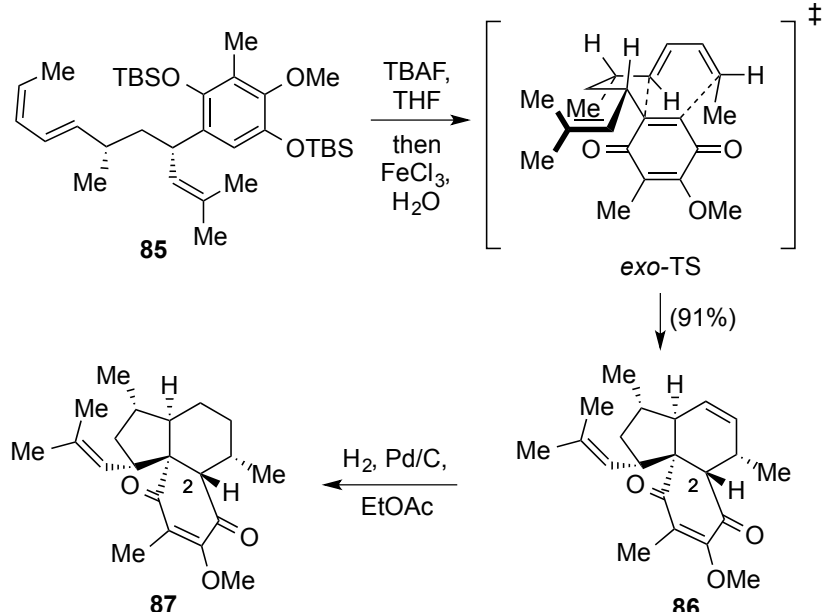

$$
\begin{array}{r|l}
\text { 1) } \mathrm{NaOH}, & \text { 2) } \mathrm{BBr}_{3}, \\
\mathrm{MeOH} & \begin{array}{l}
\mathrm{THF},-100{ }^{\circ} \mathrm{C}, \\
(27 \%, 3 \text { steps })
\end{array}
\end{array}
$$

(-)-elisabethin A

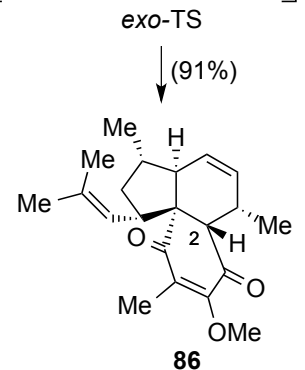

Scheme 19. Mulzer's synthesis of (-)-elisabethin A (2003).

\subsubsection{Harrowven (2005)}

The first of two syntheses of (-)-elisapterosin B and (-)-colombiasin A to appear in 2005 was published by David Harrowven's group at the University of Southampton. ${ }^{[55]}$. A similar late-stage DielsAlder reaction to those employed by Nicolaou, Rychnovsky and Jacobsen was used to form the final two rings of the natural product, although the route devised to prepare the substrate for this reaction was very different to those previously reported, and did not use any Diels-Alder chemistry. In contrast to the chiral auxiliary and asymmetric catalysis approaches previously reported, a chiral pool based approach was used, employing a Moore rearrangement as the key step to prepare the necessary quinone Diels-Alder precursor. The route began from $(S)$-dihydrocarvone, which was converted into cyclobutenone $\mathbf{8 8}$ using conventional chemistry (Scheme 20). When this compound was heated to $100{ }^{\circ} \mathrm{C}$ Moore rearrangement occurred via electrocyclic ring opening to conjugated ketene 89 that then underwent electrocyclization, tautomerization and oxidation to give quinone $90 .{ }^{[66]}$ This precursor could then be converted thermally, via quinone Diels-Alder reaction and deprotection into (-)-colombiasin A, or by treatment with $\mathrm{BF}_{3} \bullet \mathrm{OEt}_{2}$ at $-78^{\circ} \mathrm{C}$ into (-)-elisapterosin $\mathrm{B}$. 


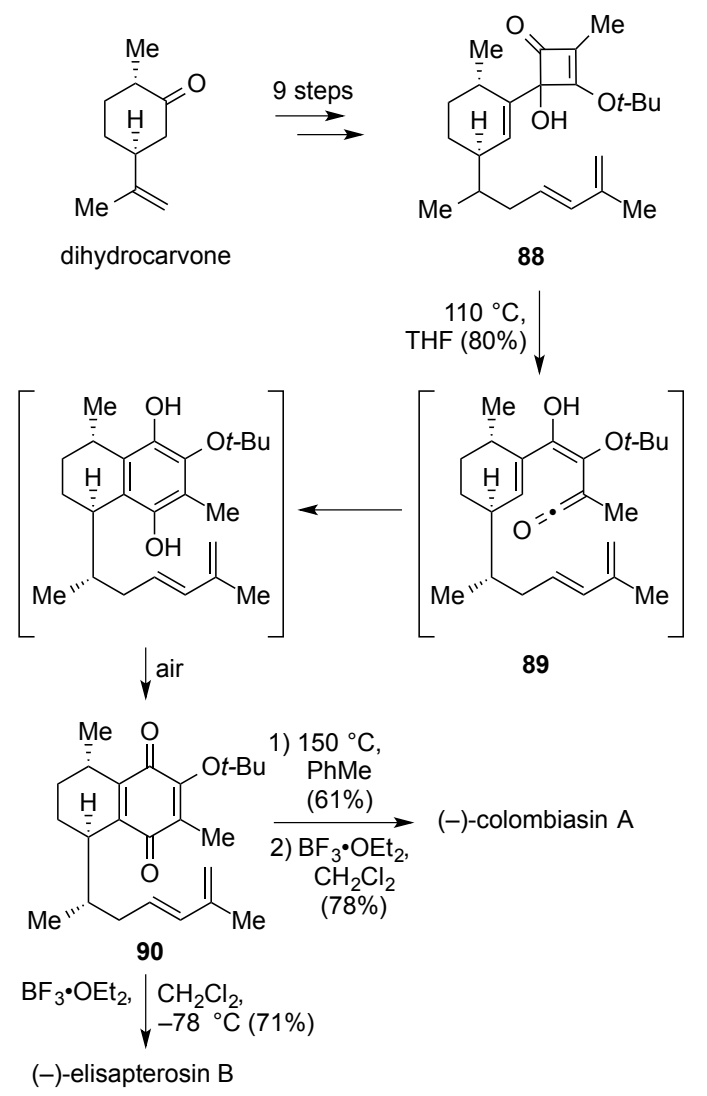

Scheme 20. Harrowven's synthesis of (-)-colombiasin A and (-)-elisapterosin B (2005).

\subsubsection{Jacobsen (2005)}

Eric Jacobsen's approach to colombiasin A and elisapterosin B was conceptually similar to that of Rychnovsky, in that the group decided to target a versatile serrulatane-type precursor that, as previously demonstrated, could be converted into either natural product ${ }^{[54]}$ This was to be constructed using an early stage quinone Diels-Alder reaction, however, instead of simply relying on substrate control from the diene component 91, the Harvard group decided to use a double stereodifferentiation approach employing both a chiral, non-racemic diene and an asymmetric catalyst (Scheme 21). The diene 91 was synthesized in four steps, including an impressive catalytic asymmetric hetero-Diels-Alder reaction between $(E)$ crotonaldehyde and ethyl vinyl ether. It was then united with benzoquinone $\mathbf{7 2}$ in the presence of 10 $\mathrm{mol} \%$ of the chromium catalyst $(1 R, 2 \mathrm{~S})-\mathbf{9 2}$ to give an $86 \%$ yield of a mixture of isomers that differed in the position of the silyl enol ether double bond. However, this was of no consequence as treatment of the mixture with concentrated hydrochloric acid in methanol gave a single hydrolysis product, obtained as a 10:1 mixture of diastereomers. Jacobsen had previously published details of the development of the Diels-Alder methodology for construction of building blocks for colombiasin synthesis, including catalyst and reaction optimization as well as the use of different dienes and dienophiles. ${ }^{[54]}$ Diastereoselective reduction of the ketone under Luche conditions gave, after aerial reoxidation of the quinone, alcohol 93. The free alcohol was then converted into the corresponding xanthate 94, which had previously been described by Nicolaou, ${ }^{[59]}$ and this was subjected to a one pot dehydration-Diels-Alder sequence that gave, after removal of the xanthate and $O$-methyl group, $(-)$-colombiasin A. Jacobsen's synthesis of this target, enabled by a powerful, bespoke asymmetric Diels-Alder methodology, is the shortest reported to date, at just 12 steps in an impressive $11.5 \%$ overall yield. 


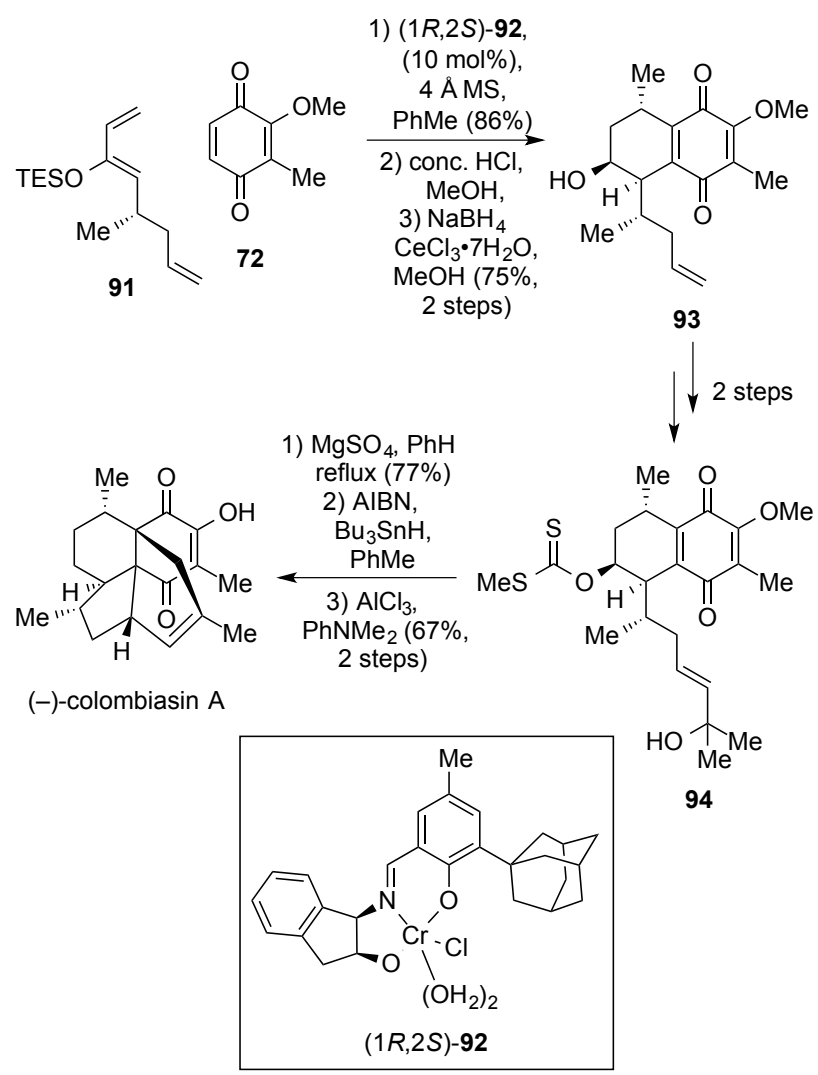

Scheme 21. Jacobsen's catalytic asymmetric Diels-Alder approach to (-)-colombiasin A (2005).

Interestingly, while investigating conditions for the demethylation step, the group discovered a previously unknown transformation; that colombiasin A could be converted into its congener elisapterosin A by simply treating with boron trifluoride diethyl etherate at room temperature (Scheme 22). This unexpected reaction represents the first successful synthesis of elisapterosin B from another natural product, and the first from a tetracyclic precursor, making this approach unique among the four syntheses of this compound reported to date.

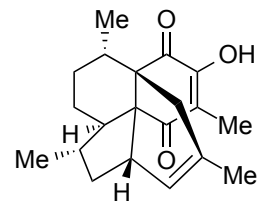

(-)-colombiasin A

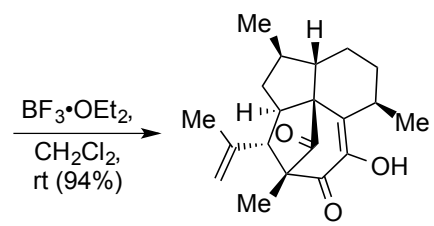

(-)-elisapterosin B

Scheme 22. Conversion of colombiasin A into elisapterosin by the Jacobsen group.

\subsubsection{Davies (2006)}

Huw Davies' route began with the same Diels-Alder reaction employed by Nicolaou above (Scheme 16), but instead focused on a more efficient method for introducing the side-chain that would later be developed into the diene required for the final [4 +2$]$ - and [5 +2]-cycloadditions. ${ }^{57]}$ The known DielsAlder adduct of diene $\mathbf{7 1}$ and benzoquinone $\mathbf{7 2}$ was converted into dihydronaphthalene 95 to which the group applied their previously reported rhodium catalyzed $\mathrm{C}-\mathrm{H}$ activation/Cope rearrangement methodology (Scheme 23). ${ }^{[67]}$ Thus, when a mixture of racemic 95 and methyl 2-diazopent-3-enoate was treated with $2 \mathrm{~mol}_{0} \mathrm{Rh}_{2}(R \text {-DOSP })_{4}$, a remarkable enantiodivergent reaction occurred where the desired enantiomer was converted into the $\mathrm{C}-\mathrm{H}$ functionalization product 96 while the unwanted enantiomer was instead converted into cyclopropane 97. Both products were formed as single diastereomers in a 1:1 ratio, but were inseparable at this stage and were therefore subjected to the subsequent hydrogenation and reduction steps as a mixture. Fortunately, after these transformations, the mixture of alcohols obtained was readily separated and the desired intermediate 98 was obtained in 34\% yield (compared to a maximum theoretical yield of $68 \%$ ) over 3 steps from dihydronaphthalene 95 in $>95 \%$ ee. Conversion of 
alcohol 98 into elisapterosin B and colombiasin A was then carried out using similar chemistry to that found in previous routes.
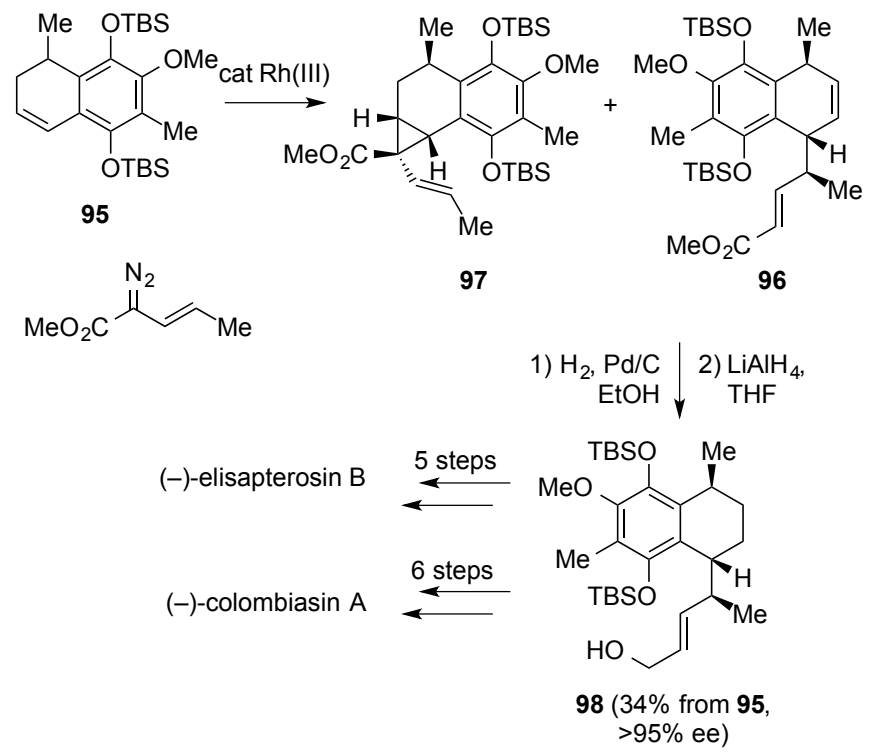

Scheme 23. Davies' C-H insertion/Cope rearrangement methodology for introduction of the diene sidechain; DOSP $=(R)-(N$-dodecylbenzenesulfonyl $)$ prolinate.

\section{Biomimetic Quinone Diels-Alder Reactions}

As well as the numerous applications found by chemists for Diels-Alder reactions with quinone dienophiles, there are a number of natural products isolated where it appears that Nature, too, has used the reaction to construct molecules. In several cases these transformations have been successfully mimicked by chemists in the laboratory, adding credence to such biosynthetic proposals and resulting in striking and efficient syntheses.

\subsection{Longithorone A (Shair, 2002)}

In 2002 Matthew Shair and co-workers at Harvard published a biomimetic total synthesis of the unusual heptacyclic natural product longithorone $A .{ }^{[68]}$ This was unique in that unlike all of the syntheses discussed so far, the quinone Diels-Alder reaction was the final step in the synthetic sequence. Although the natural product itself appears formidable, possessing both a number of contiguous stereogenic centres as well as atropisomerism resulting from hindered rotation around the lone G-ring quinone, an intriguing biosynthetic proposal by Helm and Schmitz, ${ }^{[69]}$ based on two Diels-Alder reactions, appeared to simplify the problem greatly. In order to investigate this putative biosynthetic route the two [12]-paracyclophanes 99 and 100 were prepared, both as single atropisomers, in twelve steps each (Scheme 24). A solution of these two components in dichloromethane was then treated with dimethylaluminium chloride to effect a Diels-Alder reaction that gave a 1:1.4 mixture of $\mathbf{1 0 1}$ and an unwanted diastereomer in good yield. ${ }^{[70]}$ Interestingly, this reaction, which was found to occur with complete endo-selectivity, did not proceed in the absence of a Lewis acid, possibly implicating enzymatic involvement at this stage of the biosynthesis. Next, the two TBS protecting groups were removed and the resulting phenols were oxidized to the quinones using iodosobenzene in aqueous acetonitrile. However, the expected bis(quinone) 102 was not isolated, as it apparently underwent a spontaneous transannular Diels-Alder reaction to give longithorone A in excellent yield. 

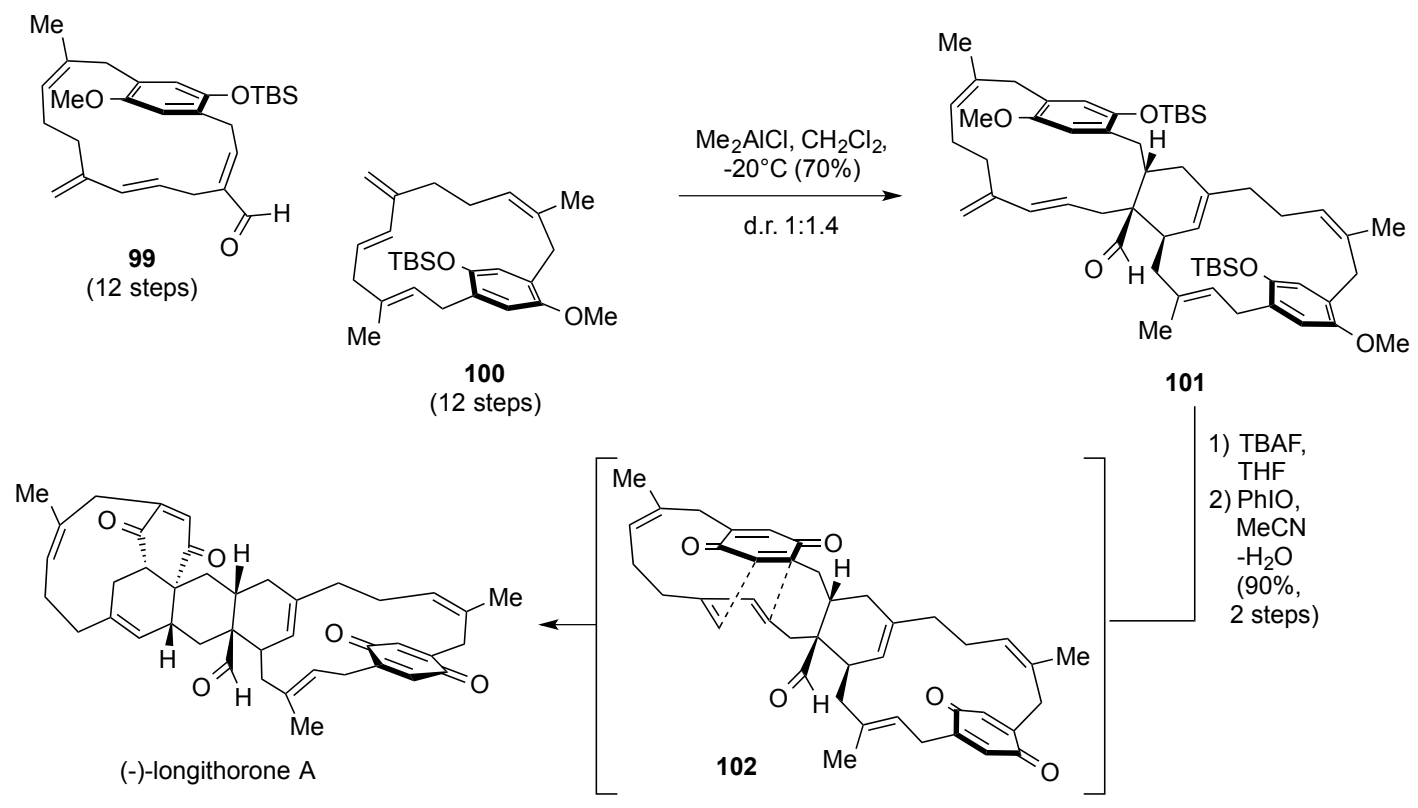

Scheme 24. Shair's 2002 biomimetic total synthesis of (-)-longithorone A 90.

\subsection{Perovskone (Majetich, 1994/2011)}

In 2011 George Majetich and co-workers at the University of Georgia reported an improved, enantioselective version of their first generation approach to the unusual triterpenoid natural product perovskone. ${ }^{[71]}$ Both routes were based on an insightful biosynthetic proposal by Ahmad and coworkers, ${ }^{[72]}$ who recognized that perovskone appeared to formally arise from the combination of an icetaxone component with a molecule of geranylpyrophosphate. Majetich and Zhang modified this idea and used the putatively biomimetic Diels-Alder reaction between icetaxone-like tricyclic benzoquinone 103 and trans- $\beta$-ocimene 104, followed by a double cyclization to form three of the rings and five of the stereogenic centres found in the natural product in a single step (Scheme 25). Under highly optimized conditions, the use of a boron trifluoride diethyl etherate catalyst in refluxing $\mathrm{CH}_{2} \mathrm{Cl}_{2}$ gave the natural product in good yield, via a breathtaking cascade of reactions.

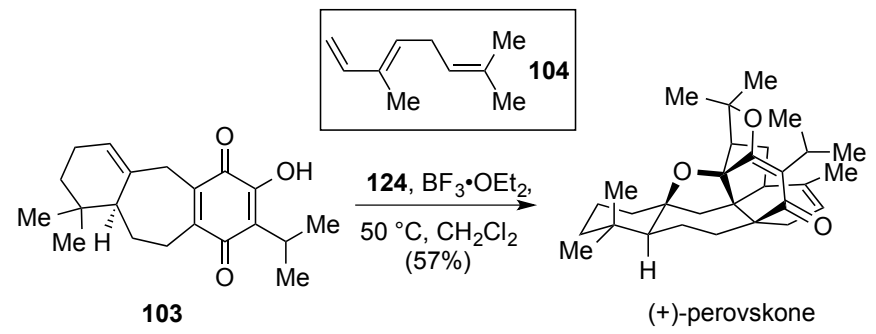

Scheme 25. Majetich's enantioselective biomimetic total synthesis of $(+)$-perovskone (2011).

\section{Naphthoquinones}

Naphthoquinones are found at the heart of a number of commercially and biologically important molecules, including a number of clinically used pharmaceuticals. ${ }^{[73]}$ Given the suitability of benzoquinones as dienophiles in the Diels-Alder reaction it should not come as a surprise that this has historically proved a popular way to construct these important compounds. From a strategic point of view, this is a desirable, central disconnection, potentially allowing for highly convergent routes, providing that suitable functionality can be included in the diene and quinone components. Although only a few examples of the Diels-Alder reaction being used to construct naturally occurring naphthoquinones appeared in the 1950-60s, the following two decades saw a significant increase of interest in this application. Key investigations by Brassard into the highly regioselective reactions of silyl ketene acetals with halogenated benzoquinones and the introduction of new dienes by Danishefsky, ${ }^{[74]}$ Rawal, ${ }^{[75]}$ Brassard $^{[78]}$ and Birch $^{[77]}$ allowed ever more complicated partners to be used. 
One of the most important families of naturally occurring naphthoquinones is the ansamycin antibiotics, in particular the rifamycins and their derivatives, which have provided humankind with a number of frontline antibiotics. ${ }^{[78]}$ Until recently, routes to the aminonaphthoquinone cores of these compounds still often employed the same long sequences of classical aromatic chemistry used in the first syntheses of these compounds some 30 years ago. ${ }^{[79]}$ However, the publication of new dienes and methodology for the rapid construction of aminonaphthoquinones through the Diels-Alder reaction of aminobenzoquinones shows that this important field is still being actively researched. ${ }^{[80]}$

Although a great number of total syntheses of naphthoquinones have been carried out using this reaction, and this topic could easily form the subject of a separate review, only two very recent, representative examples will be described here.

\subsection{Mevashuntin (Moody, 2012)}

A highly convergent route towards the unusual naphthoquinonethiazolone mevashuntin was recently developed by our own group in Nottingham (Scheme 26). ${ }^{[81]}$ The use of two highly functionalized components quinone 107 and diene 111 in the key late-stage Diels-Alder reaction meant that just two further steps were required to complete the natural product. It is worth noting that the Diels-Alder reaction gave only a single regioisomer, according to 'Brassard's rule', the empirical observation that in Diels-Alder reactions between electron rich dienes and haloquinones the most nucleophilic end of the diene becomes bound to the unhalogenated position on the quinone. ${ }^{[82]}$ The benzoquinonethiazolone dienophile 107 was prepared from the ortho-bromoaryl isothiocyanate $\mathbf{1 0 5}$ by an efficient and scalable copper mediated cyclization to give benzothiazolone $\mathbf{1 0 6}$ that was subsequently methylated and oxidized to the quinone. The pyran-containing diene 111 was prepared by magnesium methoxide mediated condensation of $\beta$-ketoester 108 with $\gamma$-functionalized acryloyl chloride 109, followed by a similar sequence of steps to those employed by Brassard in a synthesis of ventilagone. ${ }^{[82 \mathrm{e}]}$ These two components were then united in good yield using the Diels-Alder reaction, and deprotection, followed by oxidation of the primary alcohol to the acid, gave the natural product.

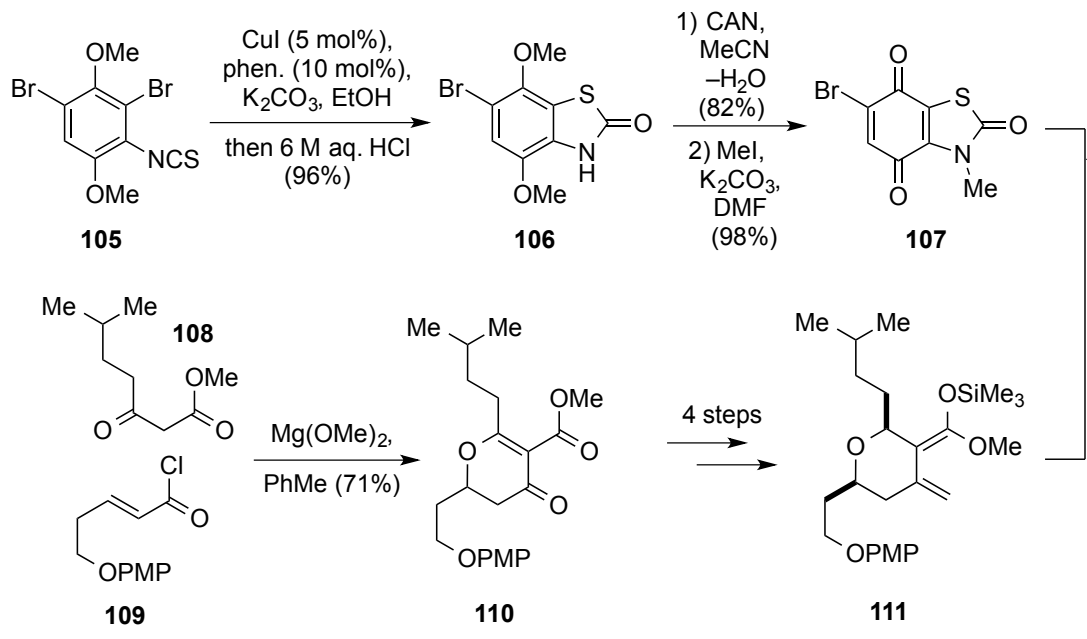

109

110

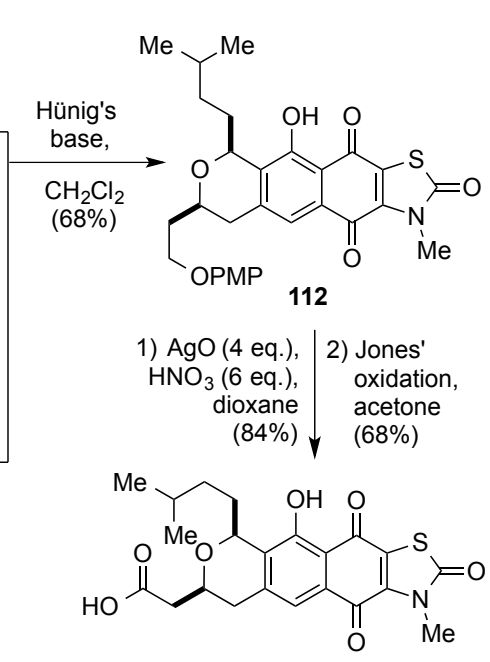

(士)-mevashuntin

Scheme 26. Moody's synthesis of the unusual quinonethiazolone mevashuntin (2012).

\subsection{Bisoranjidiol (Kozlowski, 2012)}

(S)-Bisoranjidiol was isolated from the Argentinian shrub Heterophyllaea pustulata in 2006 and its ability to act as a photosensitizer is responsible for the observed phototoxicity of this plant, which makes it a well-known hazard to grazing livestock. ${ }^{[83]}$ After ingestion, reaction with sunlight generates singlet oxygen causing damage to the skin and eyes; however, this very property has led to recent investigation of bisoranjidiol as an agent in photodynamic therapy against cancer and, along with other members of this class of natural products, it has demonstrated antibiotic activity. ${ }^{[84]}$

Marisa Kozlowski's approach to the synthesis at the University of Pennslvania hinged on the preparation of a bis-naphthoquinone precursor 116 that could then be converted into the desired bisanthraquinone by a double Diels-Alder reaction (Scheme 27$).{ }^{[85]}$ Bis-naphthoquinone 116 was prepared 
from commercially available naphthol 113 by a high yielding and highly enantioselective oxidative biaryl coupling catalyzed by the copper complex $(R, R)-\mathbf{1 1 4}$ to give $\mathbf{1 1 5}$, followed by adjustment of the substitution around the biaryl rings. Bromination was then carried out, as the presence of halogen atoms on the quinones was required to direct the Diels-Alder reaction and facilitate aromatization of the initial adducts. Unfortunately, although the bromination itself occurred in excellent yield $(95 \%)$, a mixture of regioisomeric bromides 117 and 118 was obtained. Demethylation of $\mathbf{1 1 6}$ did affect the ratio significantly, but unfortunately caused the unwanted bromide 118 to be favoured. Chromatographic separation of 117 and 118 was challenging, necessitating the use of HPLC, and resulting in the loss of some material. Next, the two bromoquinones 117 and 118 were then examined in the key Diels-Alder reaction, and were found to display markedly different reactivities. The desired, major, "out-out" bromide 117 underwent the planned Diels-Alder reaction with diene 119 over 2 days in high yield to give, after demethylation with boron tribromide, $(S)$-bisoranjidiol. Conversely, the "in-out" bromide $\mathbf{1 1 8}$ reacted much more slowly, stalling after only one cycloaddition had occurred (presumably due to a more hindered approach for the second equivalent of diene 119), producing the unnatural anthraquinone $\mathbf{1 2 0}$ only after 6 days and in a lower yield.

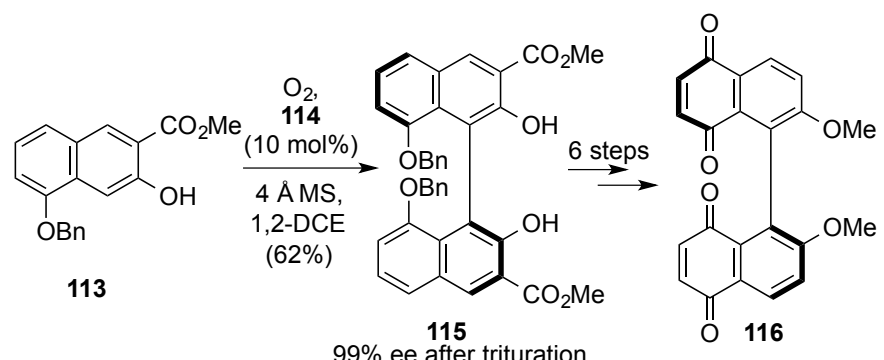

$99 \%$ ee after trituration

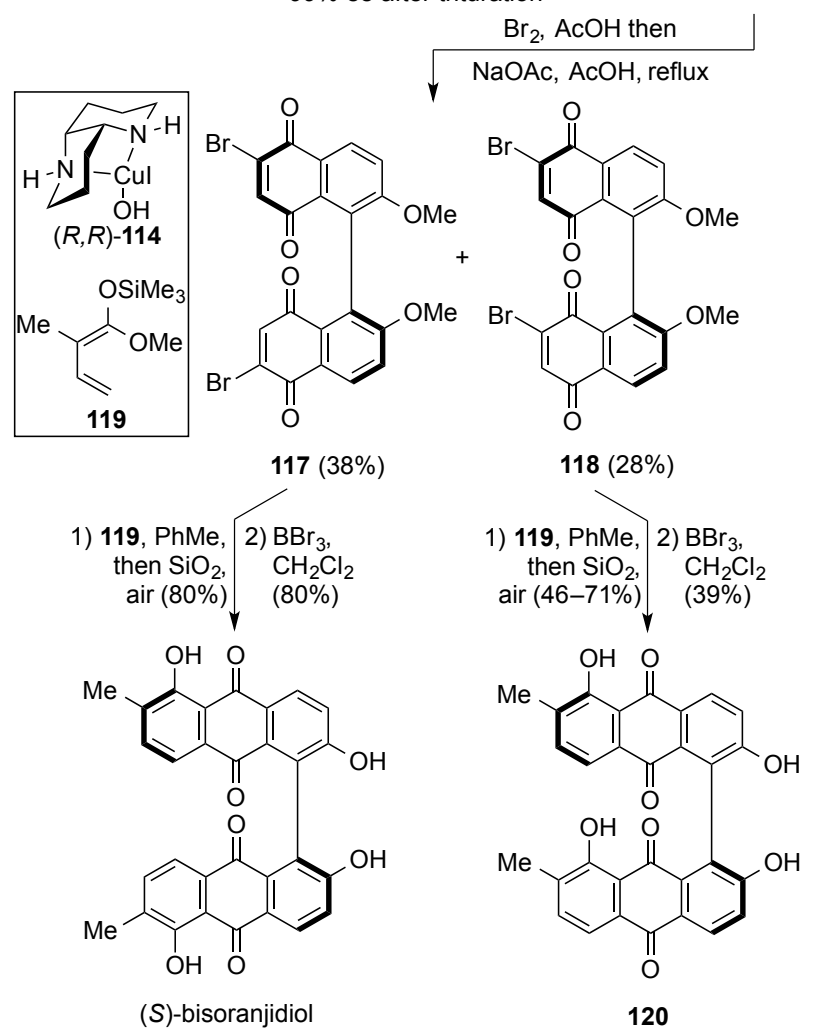

Scheme 27. Kozlowski’s “double Diels-Alder” approach to (S)-bisoranjidiol (2012).

\section{Miscellaneous}

Recently, Myers has also patented, ${ }^{[86]}$ and published ${ }^{[87]}$ a new method for preparing large $(>100 \mathrm{~g})$ quantities of the tricyclic $\mathrm{AB}$ ring enone building block that can be used for the production of tetracycline analogues, again employing the quinone Diels-Alder reaction as a key step. The quinone Diels-Alder reaction has also been used to access some quite unusual targets, being a key step in the synthesis of the highly strained hydrocarbons cubane and hypostrophene by Pettit and Paquette respectively, ${ }^{[88]}$ as well as in Eaton's synthesis of pentaprismane, ${ }^{[89]}$ the largest prismane made to date. 


\subsection{Tetracyclines (Myers, 2011)}

A highly scalable approach to chiral enone building blocks required for the synthesis of new tetracycline analogues was patented by Andrew G. Myers and co-workers at Harvard in $2010,{ }^{[86]}$ and published the following year. ${ }^{[87 b]}$ The route was based on some earlier chemistry developed by Ogasawa and co-workers, and began with the Diels-Alder reaction between silylcyclopentadiene derivative 121 and 1,4-benzoquinone (Scheme 28). ${ }^{[90]}$ Although the temporary protection of quinones through the reversible formation of Diels-Alder adducts with cyclopentadiene itself is well known, and this was originally employed by the group, the conditions for the retro-Diels-Alder reaction were harsh, low yielding and not amenable to work on large scale. For this reason, the group decided to investigate the use of an alternative diene in the hope of finding one for which the reverse reaction would be more facile. Various groups have proposed solutions to lower the temperature required for the retro-cycloaddition of norbornenyl Diels-Alder adducts; ${ }^{[91]}$ Alder himself reported the use of 1,1-dimethylfulvene for this purpose ${ }^{[92]}$ Grieco employed pentamethylcyclopentadiene to solve a similar problem in the synthesis of the prostaglandins, ${ }^{[93]}$ and Magnus developed the use of silylcyclopentadienes in studies on the Aspidosperma alkaloids. ${ }^{[94}$ After some experimentation, Myers selected dimethylphenylsilylcyclopentadiene 121, which also had the added benefit of yielding highly crystalline cycloadducts. The Diels-Alder reaction was performed by simply mixing the two components at $0{ }^{\circ} \mathrm{C}$. However, the initial cycloadduct was found to be unstable to oxidation by air, preventing the later retroDiels-Alder reaction, and so was immediately reduced in situ to give diol 122, which could be more easily isolated and handled. Enzyme mediated desymmetrization of the meso diol 122 was achieved in excellent yield, followed by an unusual palladium catalyzed elimination of $\mathbf{1 2 3}$ to give enone 124. This compound underwent annulation with the known Stork-Hagedorn isoxazole $\mathbf{1 2 5}^{[95]}$ to form key tetracyclic intermediate 126. As protection of the B-ring enol was no longer required, it was unmasked by a retro-Diels-Alder reaction carried out in toluene at reflux to give dienol 127. This compound was then converted in three steps to Myers' previously reported AB enone $\mathbf{1 2 8}$ and thence to various tetracycline derivatives such as $\mathbf{1 3 0}$ and its analogues by reaction with the D-ring precursor $\mathbf{1 2 9 .}$
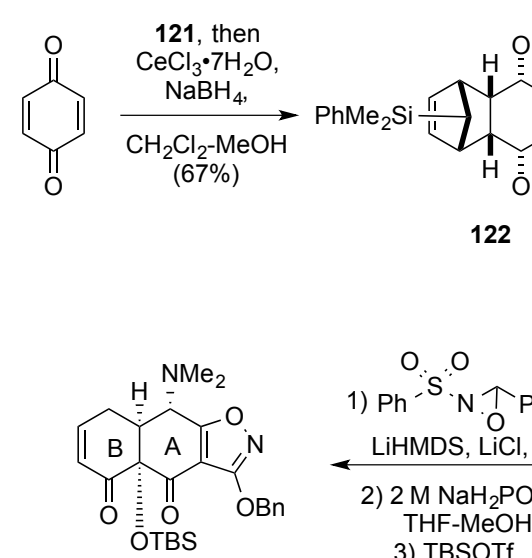

128

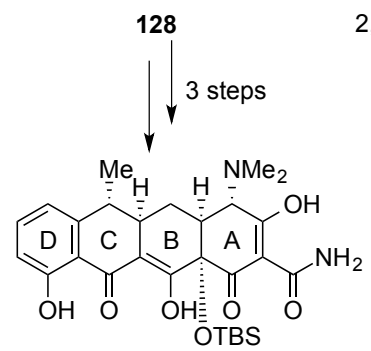

(-)-6-deoxytetracycline 130 and analogues

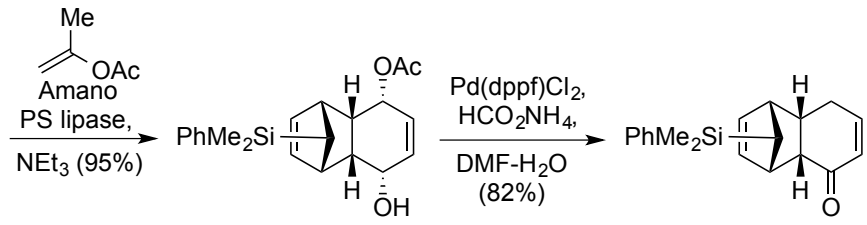

123

124

NaHMDS, then KHMDS, 125, THF (62\%)<smiles>CN(C)[C@H]1c2onc(OCc3ccccc3)c2C(=O)C2=C(O)C=CC[C@H]21</smiles>

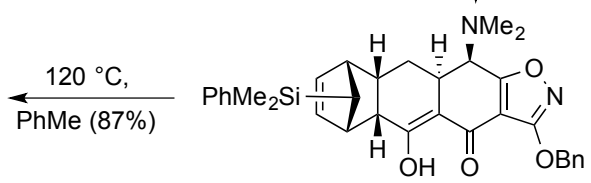

127

126

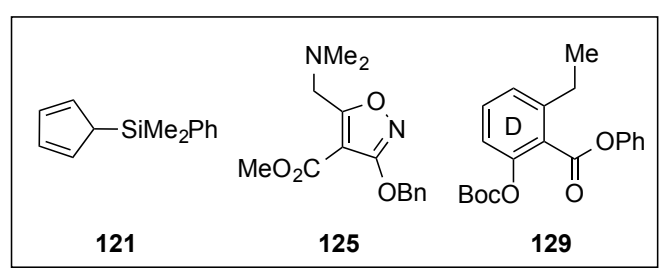

Scheme 28. Myers' approach to the enantiopure AB ring system 128 and its use in preparation of tetracycline analogues such as $\mathbf{1 3 0}$ (2011).

\subsection{Cubane (Pettit, 1966)}


A number of syntheses of the highly strained hydrocarbon cubane have been reported, ${ }^{[96]}$ but the shortest so far is that of Australian-born Rowland Pettit - who apparently managed to obtained two PhD degrees - and co-workers at the University of Texas in Austin, who required just six steps from the known 2,5-dibromobenzoquinone 131 (Scheme 29). ${ }^{[88]}$ The route began with the Diels-Alder reaction between dibromoquinone $\mathbf{1 3 1}$ and cyclobutadieneirontricarbonyl 132, ${ }^{[97]}$ a stable surrogate for the highly reactive cyclobutadiene, in the presence of CAN. Although no details for this highly unusual step were given in the original publication, a later report from the group describes an analogous reaction between 1,4-benzoquinone itself and 132 using CAN in aqueous acetone in $40-44 \%$ yield on gram scale. ${ }^{[97 a]}$ This reaction was then followed by a photochemical [2+2]-cycloaddition to form the cage-like dibromide $\mathbf{1 3 4}$. Next, a double Favorskii ring contraction using aqueous potassium hydroxide gave the cubane dicarboxylic acid 135. Finally, this was decarboxylated using the three step sequence already reported for cubane carboxylic acid by Eaton to give the target compound.

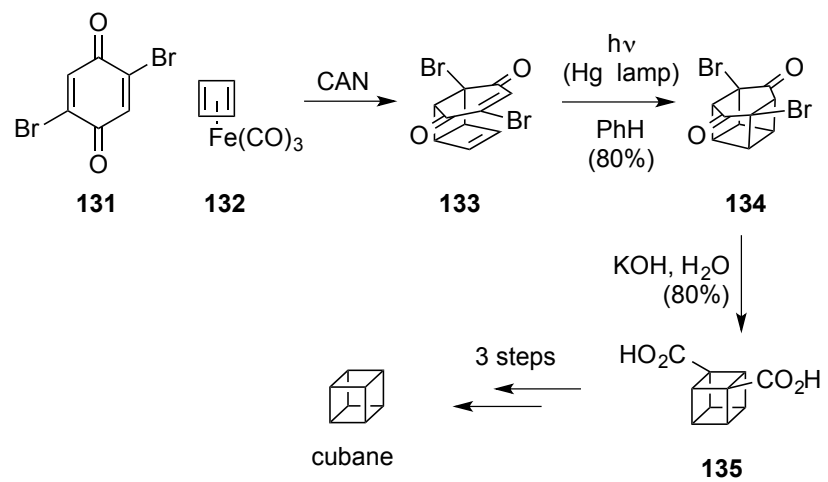

Scheme 29. Pettit's synthesis of cubane (1966).

\subsection{Pentaprismane (Eaton, 1981)}

After many unsuccessful attempts by several research groups,${ }^{[98]}$ the first total synthesis of the unnatural strained hydrocarbon pentaprismane was reported by Philip Eaton and co-workers from Chicago in $1981 .{ }^{[89]}$ Their route began with the previously reported Diels-Alder reaction between 1,4benzoquinone and the cyclopentadiene 136 (Scheme 30). The resulting diketone 137 was then subjected to a photochemical [2+2]-cycloaddition to give the caged compound 138, which was converted to tosylate 139 over a rather lengthy 12 step sequence. Finally, Favorskii rearrangement of this compound, followed by decarboxylation of acid $\mathbf{1 4 0}$ via pyrolysis of the $t$-butyl perester gave the elusive pentaprismane.
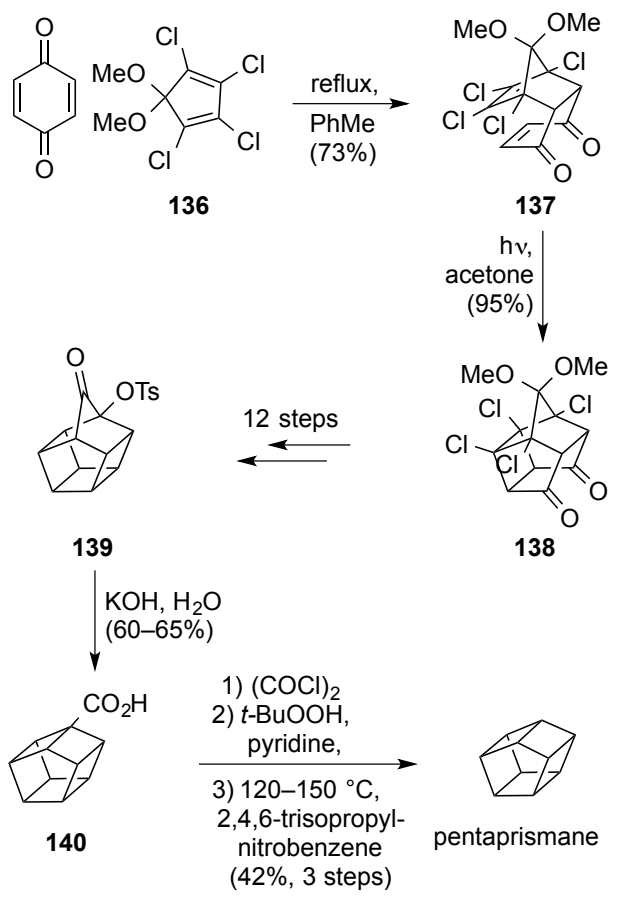
Scheme 30. Eaton's synthesis of pentaprismane (1981).

\section{Outlook}

The pivotal role that quinones have played in the discovery of the Diels-Alder reaction, as well as helping to establish its place as a uniquely powerful tool for total synthesis, cannot be denied, and the reaction has undoubtedly inspired some of the greatest organic chemists of all time. Initially, during the first two decades of its use, the quinone Diels-Alder reaction was primarily used as a tool to rapidly access functionalized decalin building blocks at the beginning of a synthetic route. Indeed, some of the best known of the syntheses discussed above, such as reserpine, tetrodotoxin and cholesterol employ it in this role. Later, in the 1970s and 1980s, the reaction began to be applied to the synthesis of naphthoquinone and anthraquinone natural products, a role to which it is almost uniquely suited, and this was aided by the development of new electron rich dienes and methods for controlling the regiochemical outcome. More recently still, the reaction has been postulated to be involved in the biosynthesis of compounds such as longithorone and perovskone, and mimicry of Nature's putative approaches to these compounds has enabled efficient syntheses of them to be achieved in the laboratory. Developments in enzymatic resolution and asymmetric catalysis mean that the quinone Diels-Alder reaction can now be used to prepare enantiopure building blocks that have found applications in both medicinal and natural products chemistry. With such myriad and diverse applications found by chemists over the past 60 years, there can be no doubt that the use of quinones as dienophiles in the Diels-Alder reaction is a powerful and enabling technology for total synthesis, and will no doubt to continue to be used as such.

Acknowledgements: we thank the EPSRC for support.

Received: ((will be filled in by the editorial staff))

Published online on ((will be filled in by the editorial staff))

[1] O. Diels, K. Alder, Liebigs Ann. Chem. 1928, 460, 98-122.

[2] T. Zincke, W. Pfaffendorf, Liebigs Ann. Chem. 1912, 394, 3.

[3] H. von Euler, K. O. Josephson, Chem. Ber. 1920, 53, 822.

[4] J. A. Berson, Tetrahedron 1992, 48, 3-17.

[5] a) G. Stork, E. E. van Tamelen, L. J. Friedman, A. W. Burgstahler, J. Am. Chem. Soc. 1951, 73, 4501-4501; b) G. Stork, E. E. van Tamelen, L. J. Friedman, A. W. Burgstahler, J. Am. Chem. Soc. 1953, 75, 384-392.

[6] R. B. Woodward, R. B. Loftfield, J. Am. Chem. Soc. 1941, 63, 3167-3171.

[7] R. B. Woodward, J. Am. Chem. Soc. 1942, 64, 3058-3059.

[8] A. R. Todd, J. W. Cornforth, Biogr. Mems. Fell. R. Soc. 1981, 27, 628-695.

[9] M. Gates, G. Tschudi, J. Am. Chem. Soc. 1952, 74, 1109-1110.

[10]R. B. Woodward, F. Sondheimer, D. Taub, K. Heusler, W. M. McLamore, J. Am. Chem. Soc. 1952, $74,4223-4251$.

[11] a) K. C. Nicolaou, S. A. Snyder, T. Montagnon, G. Vassilikogiannakis, Angew. Chem. Int. Ed. 2002, 41, 1668-1698; b) H. B. Kagan, O. Riant, Chem. Rev. 1992, 92, 1007-1019; c) G. Brieger, J. N. Bennett, Chem. Rev. 1980, 80, 63-97.

[12]W. Albrecht, Liebigs Ann. Chem. 1906, 348, 31.

[13]L. F. Fieser, M. Fieser, Steroids, Reinhold, 1959.

[14] a) R. E. Beyler, L. H. Sarett, J. Am. Chem. Soc. 1952, 74, 1406-1411; b) R. E. Beyler, L. H. Sarett, J. Am. Chem. Soc. 1952, 74, 1397-1401; c) R. M. Lukes, G. I. Poos, L. H. Sarett, J. Am. Chem. Soc. 1952, 74, 1401-1405; d) L. H. Sarett, G. E. Arth, R. M. Lukes, R. E. Beyler, G. I. Poos, W. F. Johns, J. M. Constantin, J. Am. Chem. Soc. 1952, 74, 4974-4976; e) L. H. Sarett, R. M. Lukes, G. I. Poos, J. M. Robinson, R. E. Beyler, J. M. Vandegrift, G. E. Arth, J. Am. Chem. Soc. 1952, 74, 1393-1397.

[15]R. A. Dickinson, R. Kubela, G. A. MacAlpine, Z. Stojanac, Z. Valenta, Can. J. Chem. 1972, 50, 2377-2380.

[16]K. Heusler, P. Wieland, A. Wettstein, Helv. Chim. Acta 1959, 42, 1586-1603.

[17] J. E. Cole, W. S. Johnson, P. A. Robins, J. Walker, J. Chem. Soc. 1962, 244-278. 
[18]A. J. Speziale, J. A. Stephens, Q. E. Thompson, J. Am. Chem. Soc. 1954, 76, 5011-5013.

[19]R. B. Woodward, PhD thesis, Massachusetts Institute of Technology 1937.

[20]R. B. Woodward, K. Bloch, J. Am. Chem. Soc. 1953, 75, 2023-2024.

[21] O. T. Benfey, P. J. T. Morris, Robert Burns Woodward: Architect and Artist in the World of Molecules, , Chemical Heritage Foundation, 2001.

[22] W. F. Bruce, Org. Synth. 1937, 17, 43.

[23]A. J. Birch, J. Chem. Soc. 1950, 2325-2326.

[24]L. Ruzicka, P. A. Plattner, R. Aeschbacher, Helv. Chim. Acta 1938, 21, 866-872.

[25]A. Butenandt, A. Wolff, Chem. Ber. 1935, 68, 2091-2094.

[26] a) R. M. Lukes, G. I. Poos, R. E. Beyler, W. F. Johns, L. H. Sarett, J. Am. Chem. Soc. 1953, 75 , 1707-1712; b) G. I. Poos, G. E. Arth, R. E. Beyler, L. H. Sarett, J. Am. Chem. Soc. 1953, $75,422-$ 429; c) L. H. Sarett, W. F. Johns, R. E. Beyler, R. M. Lukes, G. I. Poos, G. E. Arth, J. Am. Chem. Soc. 1953, 75, 2112-2118; d) G. E. Arth, G. I. Poos, R. M. Lukes, F. M. Robinson, W. F. Johns, M. Feurer, L. H. Sarett, J. Am. Chem. Soc. 1954, 76, 1715-1722; e) W. F. Johns, R. M. Lukes, L. H. Sarett, J. Am. Chem. Soc. 1954, 76, 5026-5030; f) G. I. Poos, R. M. Lukes, G. E. Arth, L. H. Sarett, J. Am. Chem. Soc. 1954, 76, 5031-5034; g) G. E. Arth, G. I. Poos, L. H. Sarett, J. Am. Chem. Soc. 1955, 77, 3834-3839; h) G. I. Poos, W. F. Johns, L. H. Sarett, J. Am. Chem. Soc. 1955, 77, 1026-1027.

[27]Q.-Y. Hu, G. Zhou, E. J. Corey, J. Am. Chem. Soc. 2004, 126, 13708-13713.

[28]P. Yates, P. E. Eaton, J. Am. Chem. Soc. 1960, 82, 4436-4437.

[29] a) R. Robinson, J. M. Gulland, Mem. Proc. Manchester Lit. Phil. Soc. 1925, 69, 79-86; b) J. M. Gulland, R. Robinson, J. Chem. Soc. 1923, 123, 980-998; c) J. M. Gulland, R. Robinson, J. Chem. Soc. 1923, 123, 998-1011.

[30] a) M. Gates, J. Am. Chem. Soc. 1950, 72, 228-234; b) M. Gates, G. Tschudi, J. Am. Chem. Soc. 1950, 72, 4839-4840; c) M. Gates, G. Tschudi, J. Am. Chem. Soc. 1956, 78, 1380-1393.

[31] M. Gates, R. B. Woodward, W. F. Newhall, R. Künzli, J. Am. Chem. Soc. 1950, 72, 1141-1146.

[32]N. S. Rajapaksa, M. A. McGowan, M. Rienzo, E. N. Jacobsen, Org. Lett. 2013, 15, 706-709.

[33] a) G. A. Barcan, A. Patel, K. N. Houk, O. Kwon, Org. Lett. 2012, 14, 5388-5391; b) M. Yar, M. Arshad, M. N. Ảkhtar, S. A. Shahzad, I. U. Khan, Z. A. Khan, N. Ullah, I. Ninomiya, Eur. J. Chem. 2012, 3, 26-31.

[34] a) K. C. Nicolaou, E. J. Sorensen, in Classics in Total Synthesis, Wiley-VCH, Weinheim, 1996, pp. 55-64; b) T. Hudlický, J. W. Reed, in The Way of Synthesis, Wiley-VCH, Weinheim, 2007, pp. 541573; c) I. Fleming, in Selected Organic Syntheses: A Guidebook for Organic Chemists, John Wiley \& Sons, New York, 1972, pp. 214-220.

[35]F.-E. Chen, J. Huang, Chem. Rev. 2005, 105, 4671-4706.

[36]R. B. Woodward, F. E. Bader, H. Bickel, A. J. Frey, R. W. Kierstead, J. Am. Chem. Soc. 1956, 78, 2023-2025.

[37]R. B. Woodward, F. E. Bader, H. Bickel, A. J. Frey, R. W. Kierstead, J. Am. Chem. Soc. 1956, 78, 2657-2657.

[38] S. I. Sallay, J. Am. Chem. Soc. 1967, 89, 6762-6763.

[39] J. D. White, Y. Choi, Org. Lett. 2000, 2, 2373-2376.

[40]K. Mikami, Y. Motoyama, M. Terada, J. Am. Chem. Soc. 1994, 116, 2812-2820.

[41] a) Y. Kishi, M. Aratani, T. Fukuyama, F. Nakatsubo, T. Goto, S. Inoue, H. Tanino, S. Sugiura, H. Kakoi, J. Am. Chem. Soc. 1972, 94, $9217-9219 ;$ b) Y. Kishi, T. Fukuyama, M. Aratani, F. Nakatsubo, T. Goto, S. Inoue, H. Tanino, S. Sugiura, H. Kakoi, J. Am. Chem. Soc. 1972, 94, 9219-9221; c) Y. Kishi, F. Nakatsubo, M. Aratani, T. Goto, S. Inoue, H. Kakoi, Tetrahedron Lett. 1970, 11, 51295132; d) Y. Kishi, F. Nakatsubo, M. Aratani, T. Goto, S. Inoue, H. Kakoi, S. Sugiura, Tetrahedron Lett. 1970, 11, 5127-5128.

[42]A. S. Kende, T. J. Bentley, R. A. Mader, D. Ridge, J. Am. Chem. Soc. 1974, 96, 4332-4334.

[43] a) K. Yamada, M. Suzuki, Y. Hayakawa, K. Aoki, H. Nakamura, H. Nagase, Y. Hirata, J. Am. Chem. Soc. 1972, 94, 8278-8280; b) Y. Inubushi, T. Kikuchi, T. Ibuka, K. Tanaka, I. Saji, K. Tokane, J. Chem. Soc. Chem. Commun. 1972, 0, 1252-1253; c) W. R. Roush, J. Am. Chem. Soc. 1978, 100 , 3599-3601; d) C. H. Lee, M. Westling, T. Livinghouse, A. C. Williams, J. Am. Chem. Soc. 1992, 114, 4089-4095; e) C.-K. Sha, R.-T. Chiu, C.-F. Yang, N.-T. Yao, W.-H. Tseng, F.-L. Liao, S.-L. Wang, J. Am. Chem. Soc. 1997, 119, 4130-4135; f) J. Cassayre, S. Z. Zard, J. Am. Chem. Soc. 1999, 121 , 6072-6073; g) L. M. Kreis, E. M. Carreira, Angew. Chem. Int. Ed. 2012, 51, 3436-3439; h) B. M. Trost, A. S. Tasker, G. Ruther, A. Brandes, J. Am. Chem. Soc. 1991, 113, 670-672; i) N. Uesaka, F. Saitoh, M. Mori, M. Shibasaki, K. Okamura, T. Date, J. Org. Chem. 1994, 59, 5633-5642. 
[44]a) E. J. Corey, R. L. Danheiser, S. Chandrasekaran, G. E. Keck, B. Gopalan, S. D. Larsen, P. Siret, J. L. Gras, J. Am. Chem. Soc. 1978, 100, 8034-8036; b) E. J. Corey, R. L. Danheiser, S.

Chandrasekaran, P. Siret, G. E. Keck, J. L. Gras, J. Am. Chem. Soc. 1978, 100, 8031-8034.

[45] a) A. Lang, Ann. Rev. Plant Physio. 1970, 21, 537-570; b) S. Yamaguchi, Annu. Rev. Plant Biol. 2008, 59, 225-251.

[46] V. Singh, B. Thomas, Tetrahedron 1998, 54, 3647-3692.

[47] G. Mehta, A. V. Reddy, J. Chem. Soc. Chem. Commun. 1981, 756-757.

[48] G. Mehta, A. N. Murthy, D. S. Reddy, A. V. Reddy, J. Am. Chem. Soc. 1986, 108, 3443-3452.

[49] M. Y. Chu-Moyer, S. J. Danishefsky, G. K. Schulte, J. Am. Chem. Soc. 1994, 116, 11213-11228.

[50] a) A. D. Rodríguez, C. Ramírez, Org. Lett. 2000, 2, 507-510; b) A. D. Rodríguez, C. Ramírez, I. I. Rodríguez, C. L. Barnes, J. Org. Chem. 2000, 65, 1390-1398.

[51]A. D. Rodríguez, E. González, S. D. Huang, J. Org. Chem. 1998, 63, 7083-7091.

[52] a) I. I. Rodríguez, Y.-P. Shi, O. J. García, A. D. Rodríguez, A. M. S. Mayer, J. A. Sánchez, E. Ortega-Barria, J. González, J. Nat. Prod. 2004, 67, 1672-1680; b) A. D. Rodríguez, Tetrahedron 1995, 51, 4571-4618.

[53]A. I. Kim, S. D. Rychnovsky, Angew. Chem. Int. Ed. 2003, 42, 1267-1270.

[54]A. A. Boezio, E. R. Jarvo, B. M. Lawrence, E. N. Jacobsen, Angew. Chem. Int. Ed. 2005, 44, 60466050.

[55]D. C. Harrowven, D. D. Pascoe, D. Demurtas, H. O. Bourne, Angew. Chem. Int. Ed. 2005, 44, 12211222.

[56]N. Waizumi, A. R. Stankovic, V. H. Rawal, J. Am. Chem. Soc. 2003, 125, 13022-13023.

[57]H. M. L. Davies, X. Dai, M. S. Long, J. Am. Chem. Soc. 2006, 128, 2485-2490.

[58] a) J. Mulzer, Natural Product Synthesis II: Targets, Methods, Concepts, Springer, 2005; b) M. Presset, Y. Coquerel, J. Rodriguez, Chem. Rev. 2013, 113, 525-595; c) S. P. Roche, J. A. Porco, Jr., Angew. Chem. Int. Ed. 2011, 50, 4068-4093.

[59] K. C. Nicolaou, G. Vassilikogiannakis, W. Mägerlein, R. Kranich, Angew. Chem. Int. Ed. 2001, 40, 2482-2486.

[60] C. D. Snyder, H. Rapoport, J. Am. Chem. Soc. 1972, 94, 227-231.

[61]K. C. Nicolaou, G. Vassilikogiannakis, W. Mägerlein, R. Kranich, Chem. Eur. J. 2001, 7, 5359-5371.

[62] M. A. Forman, W. P. Dailey, J. Am. Chem. Soc. 1991, 113, 2761-2762.

[63] T. J. Heckrodt, J. Mulzer, J. Am. Chem. Soc. 2003, 125, 4680-4681.

[64] T. J. Heckrodt, J. Mulzer, J. Am. Chem. Soc. 2003, 125, 9538-9538.

[65] G. Zanoni, M. Franzini, Angew. Chem. Int. Ed. 2004, 43, 4837-4841.

[66] a) J. O. Karlsson, V. N. Nghi, L. D. Foland, H. W. Moore, J. Am. Chem. Soc. 1985, 107, 3392-3393;

b) S. T. Perri, H. J. Dyke, H. W. Moore, J. Org. Chem. 1989, 54, 2032-2034.

[67] a) H. M. L. Davies, A. M. Walji, Angew. Chem. Int. Ed. 2005, 44, 1733-1735; b) H. M. L. Davies, Q. Jin, J. Am. Chem. Soc. 2004, 126, 10862-10863.

[68] a) M. E. Layton, C. A. Morales, M. D. Shair, J. Am. Chem. Soc. 2002, 124, 773-775; b) C. A. Morales, M. E. Layton, M. D. Shair, P. Natl. Acad. Sci. USA 2004, 101, 12036-12041.

[69]X. Fu, M. B. Hossain, D. van der Helm, F. J. Schmitz, J. Am. Chem. Soc. 1994, 116, 12125-12126.

[70]E. Marsault, A. Toró, P. Nowak, P. Deslongchamps, Tetrahedron 2001, 57, 4243-4260.

[71] a) G. Majetich, Y. Zhang, J. Am. Chem. Soc. 1994, 116, 4979-4980; b) G. Majetich, Y. Zhang, X. Tian, J. E. Britton, Y. L1, R. Phillips, Tetrahedron 2011, 67, 10129-10146.

[72]A. Parvez, M. I. Choudhary, F. Akhter, M. Noorwala, F. V. Mohammad, N. M. Hasan, T. Zamir, V. U. Ahmad, J. Org. Chem. 1992, 57, 4339-4340.

[73] a) R. J. O'Brien, M. A. Lyle, D. E. Snider, Rev. Infect. Dis. 1987, 9, 519-530; b) R. N. Brogden, A. Fitton, Drugs 1994, 47, 983-1009.

[74] S. Danishefsky, Acc. Chem. Res. 1981, 14, 400-406.

[75] S. A. Kozmin, M. T. Green, V. H. Rawal, J. Org. Chem. 1999, 64, 8045-8047.

[76] M. Courchesne, P. Brassard, J. Nat. Prod. 1993, 56, 722-730.

[77] A. J. Birch, J. S. Hill, J.Chem. Soc. C 1966, 419-424. 
[78]A. Bryskier, Antimicrobial Agents: Antibacterials and Antifungals, ASM Press, Washington DC, 2005.

[79] a) H. Iio, H. Nagaoka, Y. Kishi, J. Am. Chem. Soc. 1980, 102, 7965-7967; b) Y. Kishi, Pure Appl. Chem. 1981, 53, 1163-1180; c)'H. Nagaoka, Y. Kishi, Tetrahedron 1981, 37, 3873-3888.

[80] a) C. C. Nawrat, W. Lewis, C. J. Moody, J. Org. Chem. 2011, 76, 7872-7881; b) C. C. Nawrat, L. I. Palmer, A. J. Blake, C. J. Moody, J. Org. Chem. 2013, 78, 5587-5603; c) C. A. Kuttruff, S. Geiger, M. Cakmak, P. Mayer, D. Trauner, Org. Lett. 2012, 14, 1070-1073; d) S. Rasapalli, G. Jarugumilli, G. R. Yarrapothu, J. A. Golen, A. L. Rheingold, Org. Lett. 2013, 15, 1736-1739; e) S. Rasapalli, G. Jarugumılli, G. R. Yarrapothu, J. A. Golen, A. L. Rheingold, Tetrahedron Lett. 2013, 54, 2615-2618.

[81] C. C. Nawrat, C. J. Moody, Org. Lett. 2012, 14, 1484-1487.

[82] a) J. Banville, J. L. Grandmaison, G. Lang, P. Brassard, Can. J. Chem. 1974, 52, 80-87; b) B. A. Pearlman, J. M. McNamara, I. Hasan, S. Hatakeyama, H. Sekizaki, Y. Kishi, J. Am. Chem. Soc. 1981, 103, 4248-4251; c) J. Savard, P. Brassard, Tetrahedron 1984, 40, 3455-3464; d) L. Boisvert, P. Brassard, J. Org. Chem. 1988, 53, 4052-4059; e) M. Blouin, M. C. Beland, P. Brassard, J. Org. Chem. 1990, 55, 1466-1471; f) M. E. Botha, R. G. F. Giles, S. C. Yorke, J. Chem. Soc., Perkin Trans. 1 1991, 85-88; g) J. R. Grunwell, A. Karipides, C. T. Wigal, S. W. Heinzman, J. Parlow, J. A. Surso, L. Clayton, F. J. Fleitz, M. Daffner, J. E. Stevens, J. Org. Chem. 1991, 56, 91-95; h) A. B. Smith, III, J. P. Sestelo, P. G. Dormer, J. Am. Chem. Soc. 1995, 117, 10755-10756.

[83] S. C. Núñez Montoya, A. M. Agnese, J. L. Cabrera, J. Nat. Prod. 2006, 69, 801-803.

[84] a) I. Fernández, L. Comini, A. Nigra, S. Núñez, B. Rumie Vittar, J. Cabrera, V. A. Rivarola, Biocell 2009, 33, A266; b) L. R. Comini, S. C. Montoya, P. L. Paez, G. A. Arguello, I. Albesa, J. L. Cabrera, J. Photochem. Photobiol. B. 2011, 102, 108-114.

[85] a) E. E. Podlesny, M. C. Kozlowski, J. Org. Chem. 2012, 78, 466-476; b) E. E. Podlesny, M. C. Kozlowski, Org. Lett. 2012, 14, 1408-1411.

[86]A. G. Myers, D. A. Kummer, D. Li, E. Hecker, A. Dion, P. M. Wright, WO2010126607A2, 2010.

[87] a) J. D. Brubaker, A. G. Myers, Org. Lett. 2007, 9, 3523-3525; b) D. A. Kummer, D. Li, A. Dion, A. G. Myers, Chem. Sci. 2011, 2, 1710-1718.

[88]a) J. C. Barborak, L. Watts, R. Pettit, J. Am. Chem. Soc. 1966, 88, 1328-1329; b) L. A. Paquette, R. F. Davis, D. R. James, Tetrahedron Lett. 1974, 15, 1615-1618.

[89]P. E. Eaton, Y. S. Or, S. J. Branca, J. Am. Chem. Soc. 1981, 103, 2134-2136.

[90]H. Konno, K. Ogasawara, Synthesis 1999, 1135-1140.

[91]A. Ichihara, Synthesis 1987, 207-222.

[92]K. Alder, F. H. Flock, H. Beumling, Chem. Ber. 1960, 93, 1896-1899.

[93]P. A. Grieco, N. Abood, J. Chem. Soc. Chem. Commun. 1990, 410-412.

[94]P. Magnus, P. M. Cairns, J. Moursounidis, J. Am. Chem. Soc. 1987, 109, 2469-2471.

[95]G. Stork, A. A. Hagedorn, J. Am. Chem. Soc. 1978, 100, 3609-3611.

[96] a) P. E. Eaton, T. W. Cole, J. Am. Chem. Soc. 1964, 86, 3157-3158; b) M. Bliese, J. Tsanaktsidis, Aust. J. Chem. 1997, 50,189-192; c) P. E. Eaton, N. Nordari, J. Tsanaktsidis, S. P. Upadhyaya, Synthesis 1995, 1995, 501,502.

[97] a) L. Brener, J. S. McKennis, R. Pettit, Org. Synth. 1988, Coll. Vol. VI, 1002-1003; b) R. Pettit, J. Henery, Org. Synth. 1988, Coll. Vol. VI, 310-311.

[98]a) K.-W. Shen, J. Am. Chem. Soc. 1971, 93, 3064-3066; b) E. L. Allred, B. R. Beck, Tetrahedron Lett. 1974, $15,437-440$. 
Entry for the Table of Contents (Please choose one layout)

\section{Quinone Diels-Alder}

Christopher C. Nawrat and

Christopher J. Moody* Page - Page

Quinones as Dienophiles in the Diels-Alder Reaction; History and Applications in Total Synthesis
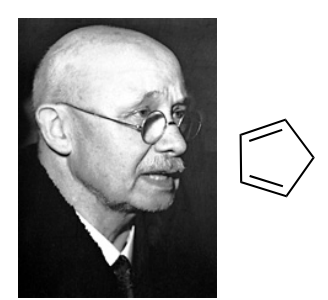<smiles>O=C1C=CC(=O)C=C1</smiles><smiles>O=C1C=CC(=O)C2C3C=CC(CC3)C12</smiles>

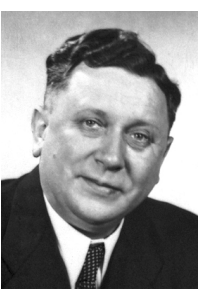

The reaction of a quinone (dienophile) with a diene was described by Diels and Alder in 1928. Herein we review the application of this reaction as a pivotal step in the synthesis of complex molecules. 